UNIVERSIDADE DE SÃO PAULO

INSTITUTO DE QUÍMICA DE SÃO CARLOS

\title{
ESTUDO NANOGRAVIMÉTRICO DAS INSTABILIDADES CINÉTICAS EM SISTEMAS ELETROCATALÍTICOS
}

MARCELO VICTOR RAGASSI

PROF. DR. HAMILTON VARELA 
MARCELO VICTOR RAGASSI

\section{ESTUDO NANOGRAVIMÉTRICO DAS INSTABILIDADES CINÉTICAS EM SISTEMAS ELETROCATALÍTICOS}

Dissertação apresentada ao Instituto de Química de São Carlos da Universidade de São Paulo como parte dos requisitos para a obtenção do título de mestre em ciências.

Área de Concentração: Físico-Química

Orientador: Prof. Dr. Hamilton Varela

São Carlos 


\section{AGRADECIMENTOS}

A Deus, por estar sempre presente e guiar o meu caminho.

À minha família, por tudo que fizeram por mim e, em momento algum, deixaram de acreditar em mim, incentivando e apoiando todas as minhas escolhas.

À Vanessa, minha namorada e futura esposa, que esteve comigo em todos os momentos e sempre me apoiou nas minhas decisões.

Ao professor e orientador Hamilton Varela, pela orientação, dedicação e amizade que foi de grande importância para a conclusão deste trabalho.

À FAPESP pelo auxílio financeiro para o meu projeto de mestrado (2016/20728-7), à CAPES e ao CNPQ.

Aos meus colegas que estiveram comigo várias horas no laboratório: Osmando, Graziela, Jéssica, Alana, Eduardo Machado, Fabian, Paula, Rafael, Bruno Previdello e Alfredo. Agradeço também aos técnicos Valdecir, Jonas, Mauro, Edson e Milton (Oficina Vidraria), Alex (Oficina Mecânica) e ao pessoal da secretaria da pós-graduação, por serem sempre atenciosos e muito prestativos todas a vezes que precisei.

A todos os amigos que não foram citados, mas também não foram esquecidos. 
"Não vos amoldeis às estruturas deste mundo, mas transformai-vos pela renovação da mente, a fim de distinguir qual é a vontade de Deus: o que é bom, o que Lhe é agradável, o que é perfeito". (Bíblia Sagrada, Romanos 12, 2) 


\section{Lista de ilustrações}

Figura 1 - Representação de uma célula a combustível. . . . . . . . . . . . . . . 11

Figura 2 - Representação de uma curva de polarização $I / \varphi$ com presença de resistência diferencial negativa. . . . . . . . . . . . . . . . 15

Figura 3 - Circuito elétrico equivalente para uma célula eletroquímica. . . . . . . 16

Figura 4 - Esquema simplificado da oxidação de metanol mostrando duas vias reacionais paralelas. (1) . . . . . . . . . . . . . . . . . . . . . 19

Figura 5 - Circuito elétrico equivalente para um ressonador de cristal de quartzo piezoelétrico.

Figura 6 - a) Perfil voltamétrico, b) variação de massa e c) da densidade de carga durante um ciclo de voltametria. Eletrólito: 0,1 M de $\mathrm{KOH}$ ou $\mathrm{LiOH}$. Velocidade de varredura de $50 \mathrm{mV} \mathrm{s}^{-1}$. . . . . . . . . . . . . . 26

Figura 7 - Variação do recobrimento de óxido sobre a superfície de platina em função do potencial para soluções de $\mathrm{KOH}$ e LiOH 0,1 M. . . . . . . . . 27

Figura 8 - a) Perfil Voltamétrico, b) Variação de massa e c) Variação da densidade de carga durante um ciclo de voltametria. Eletrólitos: 0,1 M de $\mathrm{KOH}$ ou $\mathrm{LiOH}$ e $0,1 \mathrm{M}$ de $\mathrm{H}_{3} \mathrm{COH}$. Velocidade de varredura de $50 \mathrm{mV} \mathrm{s}^{-1}$. . .

Figura 9 - Perfis de $j, \Delta$ m e q durante a varredura no sentido positivo de potencial para a eletro-oxidação de 0,1 M de metanol em 0,1 M de KOH. dE/dt $=50 \mathrm{mVs}^{-1} \ldots \ldots \ldots \ldots \ldots \ldots \ldots$

Figura 10 - Perfis de $j, \Delta \mathrm{m}$ e q durante a varredura no sentido positivo de potencial para a eletro-oxidação de 0,1 M de metanol em $0,1 \mathrm{M}$ de LiOH. dE/dt

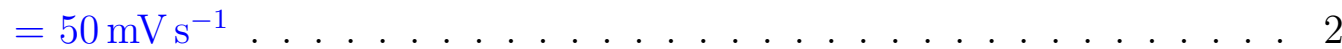

Figura 11 - a) Perfil voltamétrico, b) variação de massa durante um ciclo de voltametria contendo apenas eletrólito; c) Perfil voltamétrico e d) variação de massa durante um ciclo de voltametria após a adição de 1,0 mol.L $\mathrm{L}^{-1}$ de metanol . Eletrólito: 0,5 mol.L $\mathrm{L}^{-1}$ de $\mathrm{H}_{2} \mathrm{SO}_{4}$. Velocidade de varredura: $50 \mathrm{mV} \mathrm{s}^{-1}$

Figura 12 - Variação do recobrimento de óxido sobre a superfície de platina em função do potencial para $\mathrm{H}_{2} \mathrm{SO}_{4} 0,5$ mol.L $\mathrm{L}^{-1} \ldots$. . . . . . . . . . . 33

Figura 13 - Oscilações de potencial (em preto) e massa (em vermelho) para o sistema composto de 0,5 mol L ${ }^{-1}$ de $\mathrm{H}_{2} \mathrm{SO}_{4}$ e $1 \mathrm{~mol} \mathrm{~L}^{-1}$ de $\mathrm{H}_{3} \mathrm{COH} . j=$ $0,314 \mathrm{mAcm}^{-2} \ldots \ldots \ldots \ldots \ldots \ldots \ldots$ 
Figura 14 - a) Perfil voltamétrico, b) variação de massa durante um ciclo de voltametria contendo apenas eletrólito; c) Perfil voltamétrico e d) variação de massa durante um ciclo de voltametria após a adição de 1,0 mol.L $\mathrm{L}^{-1}$ de metanol . Eletrólito: 0,5 mol.L ${ }^{-1}$ de $\mathrm{HClO}_{4}$. Velocidade de varredura: $50 \mathrm{mVs}^{-1} \ldots \ldots \ldots \ldots \ldots$. . . . . . . . . . . . . . . . . .

Figura 15 - Oscilações de potencial (a) e massa (b) para o sistema com 0,5 mol.L ${ }^{-1}$ de $\mathrm{HClO}_{4}$ e 1,0 mol.L $\mathrm{L}^{-1}$ de metanol. i $=0,49 \mathrm{~mA}$. . . . . . . . . . . . 37

Figura 16 - a) Perfil voltamétrico, b) variação de massa durante um ciclo de voltametria contendo apenas eletrólito; c) Perfil voltamétrico e d) variação de massa durante um ciclo de voltametria após a adição de 1,0 mol.L ${ }^{-1}$ de metanol . Eletrólito: 0,5 mol.L ${ }^{-1}$ de $\mathrm{HClO}_{4}$ e $10^{-6}$ mol.L $\mathrm{L}^{-1}$ de $\mathrm{HCl}$. Velocidade de varredura: $50 \mathrm{mV} \mathrm{s}^{-1} \ldots \ldots$. . . . . . . . . . . . 38

Figura 17 - Oscilações de potencial (a) e massa (b) para o sistema com 0,5 mol.L $\mathrm{L}^{-1}$ de $\mathrm{HClO}_{4}+10^{-6}$ mol.L $\mathrm{L}^{-1}$ de $\mathrm{HCl}$ e 1,0 mol.L $\mathrm{L}^{-1}$ de metanol. $\mathrm{i}=0,49 \mathrm{~mA} 39$

Figura 18 - Procedimento utilizado para realização das medidas de transiente de potencial de circuito aberto. $\mathrm{E}_{1}$ é o potencial de polarização, mantido por $t_{1}$ segundos para garantir a formação de óxido sobre o eletrodo; $t_{2}$ é o tempo no qual acontece o transiente; $\mathrm{E}_{2}$ é o potencial de equilíbrio após o transiente; e t ${ }_{3}$ é o tempo no qual estabeleceu-se o potencial de equilíbrio. . . . . . . . . . . . . . . . . . . 4 4

Figura 19 - (a) Transiente de circuito aberto e (b) variação de massa durante transiente obtidos para $0,1 \mathrm{~mol} \mathrm{~L}^{-1}$ de metanol em $0,1 \mathrm{~mol} \mathrm{~L}^{-1}$ de $\mathrm{KOH}$ ou LiOH após a polarização do eletrodo por $60 \mathrm{~s}$ em potencial de $1,2 \mathrm{~V}$. . 42

Figura 20 - a) Transiente de potencial de circuito aberto e (b) variação de massa durante transiente obtidos para $1 \mathrm{~mol} \mathrm{~L}^{-1}$ de metanol em $0,5 \mathrm{~mol} \mathrm{~L}{ }^{-1}$ de $\mathrm{H}_{2} \mathrm{SO}_{4}$ após a polarização do eletrodo por $300 \mathrm{~s}$ em potencial de $1,4 \mathrm{~V} 44$

Figura 21 - (a) Transiente de circuito aberto e (b) variação de massa durante transiente obtidos para 0,5 mol.L ${ }^{-1}$ de $\mathrm{HClO}_{4}$ e 1,0 mol. $\mathrm{L}^{-1}$ de metanol; (c) transiente de circuito aberto e (d) variação de massa durante o transiente para o sistema composto por 0,5 mol. $\mathrm{L}^{-1}$ de $\mathrm{HClO}_{4}+10^{-6}$ mol.L $\mathrm{L}^{-1}$ de $\mathrm{HCl}$ e 1,0 mol.L $\mathrm{L}^{-1}$ de metanol, após a polarização do eletrodo por $300 \mathrm{~s}$ em potencial de $1,4 \mathrm{~V} \ldots \ldots \ldots$. . . . . . . . . . . . 45 


\section{RESUMO}

O estudo da variação de massa na superfície do eletrodo pode fornecer importantes informações a respeito de processos interfaciais. Quando bem interpretados, os resultados podem auxiliar na elucidação do mecanismo reacional. Assim, aspectos como adsorção de espécies eletroativas, formação e oxidação de adsorbatos, e processos de transferência de carga e sua dependência com o potencial podem ser avaliados. O aparecimento de instabilidades cinéticas em sistemas eletroquímicos, em particular durante a eletro-oxidação de moléculas orgânicas pequenas, tem sido tema de vários estudos. A eletro-oxidação de metanol foi estuda sobre platina em meios alcalino e ácido utilizando a técnica de nanobalança eletroquímica a cristal de quartzo. Os cátions de metais alcalinos têm um papel muito importante sobre os processos eletródicos, influenciando a formação de PtO e a corrente de oxidação do combustível. A oxidação da superfície em $\mathrm{KOH}$ é favorecida em relação ao LiOH e a variação de massa para esse processo é maior no primeiro caso. Contudo, a massa molar calculada para espécies oxigenadas na superfície foi maior para a solução contendo LiOH. Para verificar a interação da superfície de platina oxidada com o orgânico foram realizadas medidas de potencial de circuito aberto e verificou-se que na solução contendo íons $\mathrm{Li}^{+}$o tempo que antecede a íngreme queda de potencial foi maior, sendo a variação de massa durante o transiente de $-69,0 \mathrm{ng} \mathrm{\textrm {cm } ^ { - 2 }}$ e $-62,3 \mathrm{ng} \mathrm{cm}^{-2}$ para as soluções de hidróxido de potássio aquoso e hidróxido de lítio aquoso, respectivamente. Nos experimentos conduzidos em meio ácido o foco foi estudar a variação de massa durante as oscilações em condições galvanostáticas. Verificou-se que essa variação de massa foi muito pequena, cerca de $4,7 \mathrm{ng} \mathrm{cm}{ }^{-2}$, quando utilizado eletrólito aquoso de ácido sulfúrico, e com resolução relativamente boa. Em seguida etapa foi estudada a eletro-oxidação do metanol em solução de ácido perclórico na ausência e na presença de íons cloreto, sobre platina. A oxidação da superfície de plantina é adiada para potenciais um pouco mais elevado na solução contendo cloreto do que em relação àquela sem estes íons. Após a adição de metanol foi realizada uma estimativa do recobrimento de óxido na superfície para as duas situações em questão. O valor de $\theta_{O}$ encontrado foi de 3,1 e de 3,4 para a solução sem cloreto e com cloreto, respectivamente. Nos experimentos galvanostáticos, verificou-se que as oscilações de potencial e massa apresentaram frequência maior quando havia íons $\mathrm{Cl}^{-}$na solução. Com os experimentos de nanogravimetria foi possível calcular a variação de $\theta_{C O}$ durante uma oscilação. Os valores obtidos foram 0,08 e 0,12 para a solução com e sem cloreto, respectivamente. Em uma última etapa, o eletrodo foi polarizado em 1,4 V durante 300 s e em seguida abriu-se o circuito e esperou-se até que atingisse o potencial

de equilíbrio. Foi observado que o tempo para que este potencial fosse atingido foi de 9,1 s para solução sem cloreto e de $31 \mathrm{~s}$ para aquela contendo os ânions. Além disso, foi calculado o valor de $\theta_{O}$ para as duas soluções. Para a primeira o valor foi de 4,2 e para a segunda foi de 5,1. Os íons cloreto influenciam o processo de redução do óxido nos experimentos de potencial de circuito aberto durante todo o transiente devido o processo de quimissorção que ocorre e a competição com as moléculas de metanol por sítios livres. Este fenômeno também é, possivelmente, responsável pela maior variação de massa observada no transiente e consequentemente no valor de $\theta_{O}$. 


\section{ABSTRACT}

The study of the mass variation on the surface of the electrode can provide important information about interfacial processes. If there is a good interpretation, the results may aid in the elucidation of the reaction mechanism. So, aspects like adsorption of electroactive species, formation and oxidation of adsorbents, load transfer processes and their dependence on potential can be evaluated. The appearance of kinetic instabilities in electrochemical systems, particularly during the electro-oxidation of small organic molecules, has been the subject of several studies. The electro-oxidation of methanol was studied on platinum in alkaline and acid media using the technique of nanobalance electrochemical scale to quartz crystal. The alkali metal cations have a very important role on the electrodes processes, influencing the formation of $\mathrm{PtO}$ and the oxidation current of the fuel. The oxidation of the $\mathrm{KOH}$ surface is favored in relation to $\mathrm{LiOH}$ and the mass variation for this process is greater in the first case. However, the calculated molar mass for oxygenated species on the surface was higher for the solution containing LiOH. To verify the interaction of the oxidized platinum surface with the organic, open-circuit potential measurements were performed and it was found that in the solution containing $\mathrm{Li}^{+}$ions the time before the steep drop in potential was greater, corresponding during the transient mass variation of $-69.0 \mathrm{ng} \mathrm{cm}^{-2}$ and $-62.3 \mathrm{ng} \mathrm{cm}^{-2}$ for the solutions of aqueous potassium hydroxide and aqueous lithium hydroxide, respectively. In the acid experiments, the focus was to study the mass variation during oscillations under galvanostatic conditions. It was noted that this variation of mass it was very small, about $4.7 \mathrm{ng} \mathrm{cm}^{-2}$, when aqueous sulfuric acid electrolyte was used, and with relatively good resolution. Then, the electrooxidation of methanol in solution of perchloric acid in the absence and presence of chloride ions on platinum was studied.The oxidation of the plantine surface is delayed to potentials a little more high in the solution containing chloride than in relation to that without these ions, After the addition of methanol an estimation of the coating of oxidation in the surface was realized for the two situations in question. The value of $\theta_{O}$ found was 3.1 and 3.4 for the solution without chloride and with chloride, respectively. In the galvanostatic experiments, it was verified that the oscillations of potential and mass presented higher frequency when there were $\mathrm{Cl}^{-}$ions in the solution. With the nanogravimetry experiments, it was possible to calculate the variation of $\theta_{C O}$ during an oscillation. The values obtained were 0.08 and 0.12 for the solution with and without chloride, respectively. In a final step, the electrode was polarized at $1.4 \mathrm{~V}$ for $300 \mathrm{~s}$ and then the circuit was opened and waited until it reached equilibrium potential. It was observed that the time for this potential to be reached was $9.1 \mathrm{~s}$ for solution without chloride and $31 \mathrm{~s}$ for the one containing the anions. In addition, the value of $\theta_{O}$ was calculated for the two solutions. For the first, the value was 4.2 and for the second it was 5.1. The chloride ions influence in the oxidation reduction process in open circuit potential experiments throughout the transient due to the chemisorption process that occurs and competition with the methanol molecules through free sites. This phenomenon is also possibly responsible for the mass observed in the transient and consequently in the value of $\theta_{O}$. 


\section{SUMÁRIO}

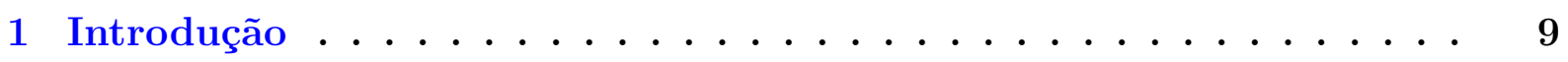

2 Conceitos ......................... 14

2.1 Dinâmica Oscilatória em Eletrocatálise . . . . . . . . . . . . . . . . . . . 14

2.2 Oxidação Eletroquímica de Metanol . . . . . . . . . . . . . . . . 16

2.2.1 Mecanismos de Reação . . . . . . . . . . . . . . . . . . . . . 18

2.3 A Técnica de Nanobalança Eletroquímica de Cristal de Quartzo . . . . . . 20

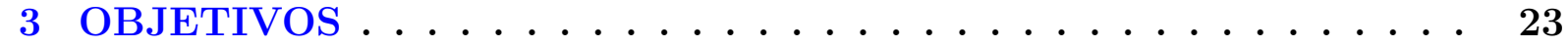

4 Eletro-Oxidação de Metanol em Meio Alcalino . . . . . . . . . . 24

4.1 Procedimento Experimental . . . . . . . . . . . . . . . . . . 24

4.2 Resultados e Discussão . . . . . . . . . . . . . . . . . . . . . 25

4.2.1 Diferenças no voltamograma base e na nanogravimetria entre soluções contendo $\mathrm{KOH}$ e $\mathrm{LiOH}$. . . . . . . . . . . . . . . . . . . 25

4.2.2 Variação de Massa durante a Eletro-Oxidação de Metanol em meio Alcalino: influência dos cátions $\mathrm{Li}^{+}$e $\mathrm{K}^{+} \ldots \ldots$. . . . . . 27

4.3 Conclusões do Capítulo . . . . . . . . . . . . . . . . . . . . . . . . . . 29

5 Eletro-Oxidação de Metanol em Meio Ácido . . . . . . . . . . . . 31

5.1 Procedimento Experimental . . . . . . . . . . . . . . . . . . 31

5.2 Metanol e Ácido Sulfúrico . . . . . . . . . . . . . . . . . . . . . 31

5.3 Metanol e Ácido Perclórico . . . . . . . . . . . . . . . . . . . 35

5.3.1 Influência de $\mathrm{ClO}_{4}^{-}$e $\mathrm{Cl}^{-}$na formação de $\mathrm{PtO}$ e durante a eletrooxidação de metanol . . . . . . . . . . . . . . . . . . . 35

5.4 Conclusões do Capítulo . . . . . . . . . . . . . . . . . . . . 39

6 Medidas de Transientes de Potencial de Circuito Aberto . . . . . . 40

6.1 Procedimento Experimental . . . . . . . . . . . . . . . . . . 40

6.2 Resultados e Discussão . . . . . . . . . . . . . . . . . . . . . . . . . . 41

6.3 Conclusão do Capítulo . . . . . . . . . . . . . . . . . 46

7 Considerações Finais . . . . . . . . . . . . . . 47

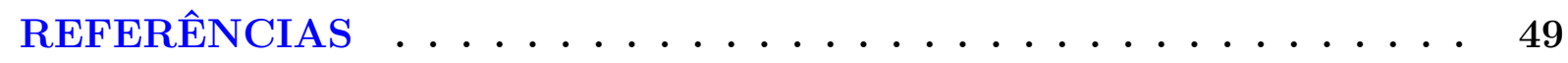




\section{Capítulo 1}

\section{Introdução}

Ao longo das décadas passadas, houve o nascimento de uma nova ciência, a física dos processos de não equilíbrio e deste modo, novos conceitos surgiram. Os termos autoorganização e estruturas dissipativas são, hoje, amplamente utilizados em estudos de cosmologia, ecologia, ciências sociais, química, biologia e várias outros (2). Os processos dissipativos são alvo do estudo da física de não equilíbrio, estes são caracterizados por um tempo unidirecional, conferindo, assim, uma nova interpretação aos processos irreversíveis.

Os processos irreversíveis estão presentes em todos os sistemas reais, como exemplos têm-se a condução de calor ou eletricidade e reações químicas. O estudo dos processos irreversíveis remete às estruturas dissipativas (3) que, como mencionado, tem como característica um tempo unidirecional, em outras palavras, trata-se da quebra de simetria temporal ou espaço-temporal. Dessa forma, a irreversibilidade torna-se condição essencial para estados coerentes em sistemas que apresentam um vasto número de moléculas. Nesse contexto, é impossível não mencionar o papel construtivo da entropia. O termo entropia deriva do grego $\epsilon \nu \tau \rho \omega \pi \eta$, que significa "evolução", logo, o desenvolver da vida encontrase vinculado à produção de entropia e, consequentemente, aos processos irreversíveis.

A coerência no tempo e espaço no mundo microscópico é traduzido no macroscópico pela formação espontânea de padrões auto-organizados (4). Estes fenômenos são frequentemente encontrados na natureza abrangendo sistemas físicos, químicos e biológicos. $\mathrm{O}$ próprio ser humano, por sua complexidade, pode ser usado para mostrar como a autoorganização e formação de padrões estão presentes no dia a dia. As oscilações neurais (5) e os ritmos circadiano e ultradianos (6-8) são importantes exemplos que podem ser citados. No ramo das ciências, reações químicas são afastadas de seu estado de equilíbrio, sendo assim muito comum verificar processos não lineares, comportamento caótico, formação de padrões espaço-temporais. 
A cinética dos processos eletroquímicos está fundamentada nos fenômenos que ocorrem na região fronteiriça entre o condutor eletrônico (eletrodo) e o condutor iônico (eletrólito). A interface eletrodo/solução foi pela primeira vez descrita por Helmholtz em 1853, quando ele propôs um modelo aproximado de um capacitor de placas paralelas, onde, obviamente, não há existência física da placa no lado da solução. Posteriormente, o modelo de Gouy-Chapman sobre a dupla camada foi denominado de modelo da camada difusa, justamente por considerar que os íons que formam a placa do capacitor no lado da solução não são fixos (9). Assim, para um determinado potencial, existirá uma certa carga $\left(q^{M}\right)$ no metal que constitui o eletrodo e uma carga oposta na região da solução $\left(q^{S}\right)$. A este arranjo de cargas e dipolos dispostos na região de interface dá-se o nome de dupla camada elétrica.

Uma grande atenção vem sendo dada à eletro-oxidação de moléculas orgânicas pequenas $(1,10,11)$ em virtude de sua relevância na interconversão entre energias química e elétrica. Moléculas como metanol, formaldeído e ácido fórmico apresentam vantagens como facilidade de manuseamento e armazenamento, além da grande densidade de energia. Não obstante, estas espécies apresentam algumas desvantagens, entre outras, como a necessidade de um metal nobre para catalisar a reação; e a produção de intermediários que podem envenenar o eletrodo, sendo esta a principal limitação para uma célula à combustível de baixa temperatura alimentada com combustível líquido (12).

As células a combustível são dispositivos cuja função é converter a energia química de um combustível em energia elétrica por meio de uma reação auxiliada por um catalisador (13). Entre os vários tipo de células a combustível, a de metanol direto (do inglês, Direct Methanol Fuel Cell - DMFC) tem apresentado um rápido desenvolvimento. Isto é devido à sua estrutura simplificada (Figura 1), baixa poluição, rápida operação e alta densidade de energia. $\mathrm{Na} \mathrm{DMFC}, \mathrm{o} \mathrm{H}_{3} \mathrm{COH}$ é utilizado como combustível no ânodo e o $\mathrm{O}_{2}$, no cátodo, de modo que para a produção da eletricidade não necessite de um reformador ou umidificador. Devido suas características, a DMFC passa a ser uma candidata promissora para ser utilizada em dispositivos portáteis. Teoricamente, a densidade de energia da DMFC é 15 vezes maior do que as baterias de íon-lítio (14).

A eletro-oxidação do metanol no ânodo gera dióxido de carbono $\left(\mathrm{CO}_{2}\right), 6$ prótons e 6 elétrons. Embora o metanol possa chegar à dióxido de carbono por várias rotas, a preferida é aquela que contém compostos estáveis, tais como formaldeído ( $\mathrm{HCOH}$ ) e ácido fórmico $(\mathrm{HCOOH})(13)$. Essa reação pode gerar monóxido de carbono (CO) como intermediário que age como veneno nos catalisadores de platina. Assim, com os sítios reacionais ocupados pelo $\mathrm{CO}$ a velocidade da reação de oxidação do metanol é diminuída (14). Para contornar esse problema, diversos estudos envolvendo catalisadores constituídos por ligas de platina com outros metais foram realizados (15), sendo a liga 1:1 de Pt-Ru uma das mais usadas no ânodo das DMFCs (16). As moléculas que contém oxigênio adsorvem nos átomos de $\mathrm{Ru}$, facilitando a oxidação do $\mathrm{CO}$ em $\mathrm{CO}_{2}$ (14). Já o 
Figura 1 - Representação de uma célula a combustível.

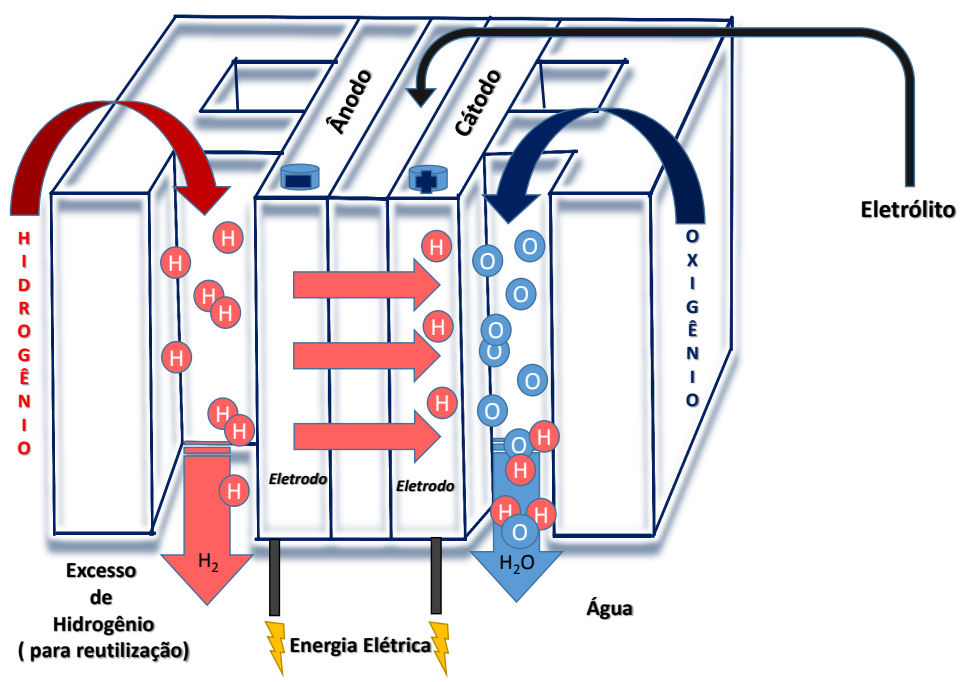

Fonte: Autoria Própria

efeito eletrônico relaciona a presença do segundo metal com a variação no centro da banda d da platina, de modo que a posição central dessa banda correlaciona-se com a energia de adsorção de um determinado adsorbato. Assim, uma maior tolerância ao CO para a liga $\mathrm{Pt} / \mathrm{Ru}$ em relação à $\mathrm{Pt}$ pura pode ser imputada à menor energia de adsorção de $\mathrm{CO}$ sobre Pt, por consequência de uma mudança do centro de banda d, uma vez que quanto maior a energia do centro da banda d, maior a energia de interação Pt-CO.

Em resumo, o sucesso de uma célula a combustível se deve a dois materiais-chave: a membrana que separa o cátodo e o ânodo e os catalisadores metálicos (17). Consequentemente, os maiores desafios enfrentados pelas DMFCs estão direcionados para esses dois materiais, são eles: o crossover do metanol, que é definido como a passagem do metanol através da membrana no sentido ânodo $\rightarrow$ cátodo e pode ser superado pelo desenvolvimento de novas membranas ou cátodos tolerantes ao metanol; e a lenta cinética anódica, que pode ser vencida desenvolvendo novos catalisadores para serem empregados no ânodo $(14,15)$.

Há uma limitação quanto aos materiais que podem ser utilizados como eletrodo para reação de eletro-oxidação do metanol, especialmente em meio ácido. As ligas platina/rutênio apresentam as melhores atividades e estabilidade que as tornam viáveis para o emprego em DMFCs (15). Para um catalisador de platina pura, o envenenamento por CO, um dos intermediários da reação de oxidação do metanol, por subtrair um sítio reacional ativo, diminui a taxa da reação. Com a introdução de um segundo metal, como o rutênio, ligado à platina, a cinética de oxidação do metanol é melhorada significativamente. Esse aumento de atividade proporcionado pela liga $\mathrm{Pt} / \mathrm{Ru}$ é atribuído a dois fatores: um mecanismo bifuncional (18) e o efeito eletrônico do ligante (19). O meca- 
nismo bifuncional envolve adsorção de espécies portadoras de oxigênio nos átomos de $\mathrm{Ru}$ em potenciais mais baixos, promovendo a oxidação de $\mathrm{CO}$ a $\mathrm{CO}_{2}$ (15).

O problema trazido pelo crossover do metanol é a queda do desempenho da célula. $\mathrm{Na}$ presença do metanol, o oxigênio é reduzido no cátodo já em potencial de circuito aberto e uma quantidade equivalente de metanol é oxidada. Esse processo dá origem a formação de um potencial misto (20). Além do consumo do combustível e do oxigênio com a formação do potencial misto, uma reação puramente química acontece na superfície do catalisador de platina. Para estudar essa problemática, Sitta e Varela (21) investigaram a interação das moléculas de metanol com o eletrodo de platina oxidado em termos do transiente de potencial de circuito aberto. Em seus experimentos, o eletrodo de trabalho foi inicialmente polarizado em $1,4 \mathrm{~V}$ em diferentes tempos antes da introdução do metanol no sistema e abertura do circuito. Diferentemente de outros trabalho, os autores variaram as condições de pré-oxidação da platina: utilizaram como eletrólito de suporte 0,5 mol.L $\mathrm{L}^{-1}$ de $\mathrm{H}_{2} \mathrm{SO}_{4}, 0,1$ mol.L ${ }^{-1}$ de $\mathrm{HClO}_{4}$ e 0,5 mol.L ${ }^{-1}$ de $\mathrm{H}_{2} \mathrm{SO}_{4}+10^{-4} \mathrm{~mol} . \mathrm{L}^{-1}$ de $\mathrm{Cl}^{-}$. Assim, foi possível concluir que quanto maior a energia de quimissorção do ânion,mais longo foi o transiente de potencial de circuito aberto. Além disso, relataram que a forma dos transientes foram praticamente iguais, independentemente da identidade do ânion presente. A interpretação desses resultados levaram os pesquisadores a concluírem que há uma dependência da disponibilidade de sítios livres de platina durante todo o período do transiente e não apenas ao longo da região em que a cobertura de oxigênio é pequena.

Sabendo da importância da dupla camada na eletroquímica, torna-se fundamental o conhecimento dos fluxos de massa e carga através da interface eletrodo/solução de modo a obter um conhecimento de como esses parâmetros afetam a transferência de carga. A técnica in situ de Nanobalança Eletroquímica de Cristal de Quartzo (NECQ) tem sido utilizada em diversos trabalhos para monitorar diversos processos eletroquímicos como a eletrodeposição de metais $(22,23)$, corrosão $(24,25)$, adsorção (26-28), estudos sobre formação de camadas de óxido sobre metais $(29,30)$ e sistemas que apresentam dinâmica complexa (10). Neste contexto, Tian e Conway (2008) (31) relataram um estudo sobre a eletro-oxidação oscilatória de ácido fórmico e ânions formiato sobre platina. A NECQ mostrou grande relevância, de acordo com os autores, devido à possibilidade de detectar e medir variações de massa superficial durante uma única oscilação de potencial. Eles mostraram que o período antecedente à queda abrupta de potencial nas oscilações é marcado por uma diminuição de massa de $67 \mathrm{ng} \mathrm{cm}^{-2}$ e durante a queda ocorre um aumento da massa superficial de $146 \mathrm{ng} \mathrm{cm}^{-2}$.

No tocante às instabilidades cinéticas que ocorrem no processo de eletro-oxidação de moléculas orgânicas pequenas, além de ser um fenômeno incrivelmente interessante no ponto de vista científico, as oscilações que surgem espontaneamente, podem ser utilizadas para um estudo acerca dos mecanismos das reações. Ademais, as instabilidades dão lugar a um mecanismo de self-cleaning (autolimpeza) da superfície do catalisador, aumentando, 
assim, a vida útil do catalisador e a eficiência do processo (32).

Este trabalho está organizado da seguinte maneira. O capítulo 2 é dedicado a uma apresentação geral da dinâmica oscilatória em eletrocatálise: responde à questão do surgimento das instabilidades cinéticas em sistemas eletrocatalíticos relacionando-o a existência de uma resistência diferencial negativa na curva de polarização da corrente pelo potencial. Na sequência é feita a introdução de algumas equações fundamentais para o estudo de eletrocatálise. Também é dissertado sobre a relação entre a competição por sítios livres na superfície do eletrodo e o comportamento não linear nas reações de eletrooxidação de moléculas orgânicas pequenas. No mesmo capítulo, mais adiante, encontramse descritos o processo de eletro-oxidação do metanol e os mecanismos de reações que são similares para as moléculas orgânicas pequenas. No final do capítulo 1, é apresentada a técnica de nanogravimentria que utiliza a nanobalança eletroquímica de cristal de quartzo, mostrando alguns exemplos de aplicação. O capítulo 3 traz os objetivos deste trabalho. O capítulo 4 apresenta os resultados de nanogravimetria para os experimentos de eletrooxidação de metanol em meio alcalino, abordando as diferenças entre o uso $\mathrm{KOH}$ e LiOH como eletrólito de base. No capítulo 5 os resultados de nanogravimetria para a eletrooxidação de metanol são mostrados para o meio ácido. Neste caso foram usados diferentes eletrólitos ácidos, com o intuito de verificar a diferença na variação da massa superficial durante a eletro-oxidação do metanol em regime oscilatório conforme variava-se a energia de adsorção dos ânions em solução. O capítulo 6 encerra a parte dos resultados do trabalho apresentando os resultados para as medidas para os transientes de potencial após a abertura do circuito. Essa abordagem visa à quantificação da quantidade de óxido formado na superfície do catalisador e, também, quantificar a quantidade de CO formada após a interação química do metanol com a platina oxidada. O último capítulo é dedicado às considerações finais. 


\section{Capítulo 2}

\section{Conceitos}

\subsection{Dinâmica Oscilatória em Eletrocatálise}

Quando um sistema é suficientemente afastado do estado de equilíbrio termodinâmico configura-se a condição fundamental à emergência de dinâmica não-linear. Nesse contexto, a irreversibilidade dos processos é a personagem principal, propiciando o surgimento de ordem, ou seja, a formação de padrões auto-organizados (33). Em seu livro "O Fim das Certezas", Ilya Prigogine (2) aborda sobre o papel construtivo dos processos irreversíveis na natureza, enfatizando ainda que estes não devem mais ser associados com o aumento da desordem, como assim era feito, desde a formulação da segunda lei da termodinâmica com o conceito de entropia.

O contato com fenômenos que apresentam dinâmica não linear é constante no dia a dia dos seres humanos. Na química, a maioria das reações apresentam cinética não linear. Outras, auto-organização. Neste caso, um dos mais famosos experimentos, que lida com oscilações periódicas, é a reação de Belousov-Zhabotinsky (BZ) (34). Já para a eletroquímica os processos apresentam essencialmente características não lineares, como pode ser visto pela própria equação de Butler-Volmer (9) que relaciona a dependência exponencial da corrente elétrica com o sobrepotencial aplicado nas reações eletródicas. Assim, além das espécies químicas presentes em um sistema eletroquímico, o potencial do eletrodo é uma variável fundamental na descrição de instabilidades cinéticas.

$\mathrm{Na}$ presença de pequenas flutuações, em geral, há duas alternativas: (i) este se mostrará insensível, significando que encontra-se em um estado estável e, deste modo, mesmo que a perturbação o afaste do estado estacionário o sistema retornará para o seu estado estável após a perturbação ter cessado, ou (ii) se o sistema encontrar-se, a priori, em um estado instável, mesmo a mínima flutuação é capaz de retirá-lo do seu estado 
estacionário. Frequentemente, quando há uma mudança de um estado estável para um instável o sistema passa por uma bifurcação (35). Pode-se dizer que uma bifurcação é um ponto em que ocorre uma transição qualitativa do comportamento do sistema (36). Para o caso do surgimento de oscilações, a bifurcação leva à perda de estabilidade do estado estacionário que, em sistemas eletroquímicos, pode surgir devido à variação de parâmetros como resistência externa, potencial total ou corrente aplicada.

Retomando a questão sobre o aparecimento das instabilidades cinéticas em processos eletrocatalíticos, estas relacionam-se com a dependência da corrente $(I)$ com o potencial do eletrodo $(\varphi)$ em forma de $N$. Esta configuração deve-se ao fato de existir uma resistência diferencial negativa (NDR - referente à nomenclatura em inglês Negative Differential Resistance) na curva de polarização $I / \varphi$ (Figura 2). No entanto, qual é a origem da NDR?

Figura 2 - Representação de uma curva de polarização $I / \varphi$ com presença de resistência diferencial negativa.

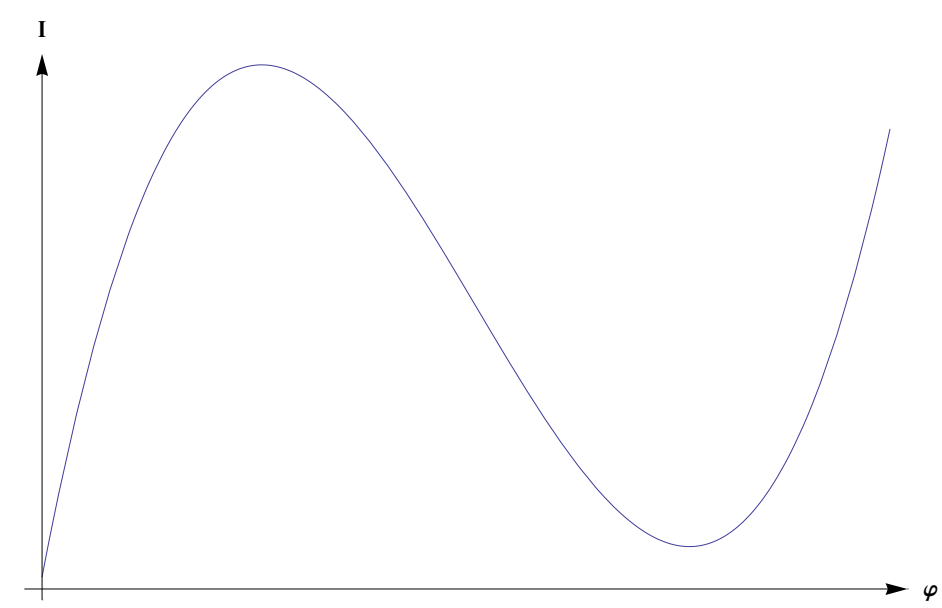

Para responder essa questão, primeiramente, deve-se assumir que a corrente elétrica que atravessa o eletrodo de trabalho possui duas componente, uma de origem capacitativa e outra faradaica. A Figura 3 mostra um circuito equivalente para uma célula eletroquímica. Aplicando a lei das malhas, ou lei de Kirchhoff, obtém-se a equação fundamental utilizada para a análise de estabilidade dos sistemas eletroquímicos:

$$
I=\frac{U-\varphi}{R_{s}}=I_{f}(\varphi)+I_{c}(\varphi)=I_{f}(\varphi)+C_{d} \frac{d \varphi}{d t},
$$

em que $I_{f}$ representa a corrente faradaica, ou seja, aquela associada a processos de transferência de carga, $I_{c}$ a corrente capacitiva, que está relacionada com o rearranjo de carga na dupla camada, $U$ é a voltagem aplicada pelo potenciostato, a qual é considerada constante para este caso, $R_{s}$ é a resistência da solução eletrolítica e qualquer outra associada ao circuito elétrico (em série com o eletrodo de trabalho) e $C_{d}$ é a capacitância associada 
Figura 3 - Circuito elétrico equivalente para uma célula eletroquímica.

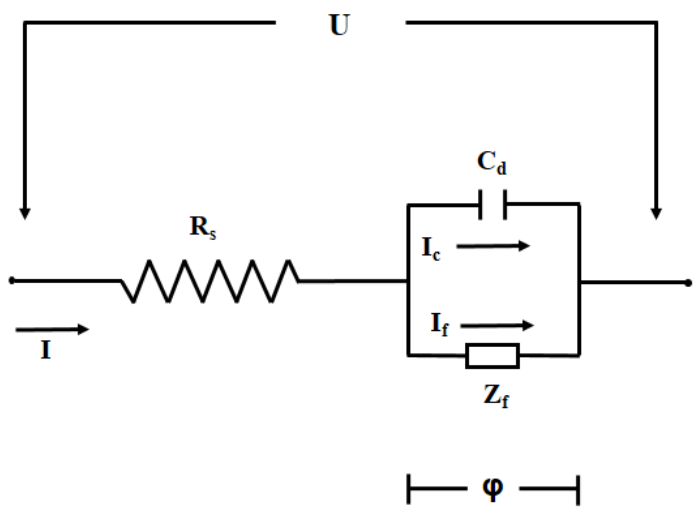

com a dupla camada elétrica. A expressão geral para a corrente faradaica pode ser dada como: (37):

$$
I_{f}(\varphi)=n F A(\varphi) c(\varphi) k(\varphi)
$$

e a expressão para impedância faradaica (38) é:

$$
Z_{f}^{-1}=\frac{d I_{f}(\varphi)}{d \varphi}=n F\left(c k \frac{d A}{d \varphi}+A k \frac{d c}{d \varphi}+A c \frac{d k}{d \varphi}\right)
$$

em que $n$ é o número de elétrons transferidos, $F$ é a constante de Faraday, $A$ é a área do eletrodo disponível para reação, $k$ é a constante cinética para o processo e $c$ é a concentração da espécie reagente na superfície do eletrodo. Assim, a existência de uma região de impedância negativa, que é evidenciada na equação (2.3), apresenta três possíveis causas: (i) $d A / d \varphi<0$; (ii) $d c / d \varphi<0$; ou (iii) $d k / d \varphi<0$ (37).

A emergência de comportamento não linear nas reações eletrocatalíticas está normalmente relacionada com a competição por sítios livres na superfície entre diferentes espécies e a dependência de suas isotermas de adsorção com o potencial. No entanto, na ausência de outros ciclos de retroalimentação, a autocatálise no potencial do eletrodo pode ser responsável pela biestabilidade (i.e. presença de dois estados estáveis para um mesmo conjunto de parâmetros). Contudo, um ciclo de retroalimentação negativa pode originar oscilações periódicas (37). Já oscilações de modo misto e caos podem emergir de um grau de liberdade adicional, i.e. um aumento da dimensão do espaço de fase (35).

\subsection{Oxidação Eletroquímica de Metanol}

A voltametria cíclica é uma técnica eletroquímica muito utilizada nos estudos das reações que ocorrem nas células a combustível. Muito frequentemente, o grau de recobrimento da superfície do catalisador metálico por intermediários de reação e ad-átomos é investigado por varredura que abrange a região de adsorção/dessorção de hidrogênio. A 
carga originada por meio do processo de adsorção/dessorção de hidrogênio dá a área eletroativa da platina (catalisador) (12). O acoplamento das técnicas de voltametria cíclica (CV) com a nanobalança eletroquímica de cristal de quartzo pode levar a determinações in situ da natureza das espécies adsorvidas na interface $(27,39)$, conquanto esse processo não é fácil, pois há vários outros acontecendo simultaneamente.

Compostos orgânicos simples como metanol, formaldeído e ácido fórmico apresentam grandes vantagens considerando seus usos como combustível. Eles são fáceis de manusear, de armazenar e possuem uma alta densidade de energia, da ordem de $1 \mathrm{kWh} / \mathrm{kg}$ (40). Outro ponto positivo destes combustíveis é que no caso de uma crise energética eles podem ser produzidos a partir de biomassa. Por fim, por apresentar uma estrutura simples eles devem apresentar o mais simples mecanismo de reação dentre todos os possíveis combustíveis orgânicos. O metanol e os outros combustíveis apresentam também desvantagens: por causa da baixa densidade de corrente de troca na maioria dos eletrodos, eles são muito menos ativos do que o $\mathrm{H}_{2}$, e, portanto, precisam de um eletrodo de metal nobre, como a Pt.

As primeiras pesquisas com combustíveis no âmbito das células a combustível, houve uma certa preferência pelo metanol. Isso se deve ao fato de sua oxidação completa fornecer seis elétrons ao invés de quatro e dois como o formaldeído e o ácido fórmico, respectivamente. Além do mais, o formaldeído apresenta uma certa instabilidade.

Os primeiros estudos com infravermelho (IV) durante a oxidação de metanol sobre monocristais de platina (41) revelaram três espécies de adsorbatos na superfície do eletrodo: CO ligado linearmente, em ponte e espécies do tipo formil. As proporções de cada espécie, bem como a dependência da oxidação do CO com o potencial estão relacionadas com a face do cristal (42).

Muitos estudos têm mostrado que o CO é o veneno catalítico formado durante a oxidação do metanol e que espécies como $\mathrm{CHO}$ e $\mathrm{COH}$ são intermediários da reação $(12,43)$, uma vez que estes apresentam-se mais fracamente ligados à superfície do que aquele. A adsorção de ânions é também um sério problema relatado na oxidação de metanol em eletrólito ácido. O grau de recobrimento mostra-se decrescente de acordo com o eletrólito, na ordem $\mathrm{NO}_{3}^{-}, \mathrm{SO}_{4}^{2-}, \mathrm{ClO}_{4}^{-}$(44). Dessa forma, as corrente obtidas em $\mathrm{H}_{2} \mathrm{SO}_{4}$ são menores do que as obtidas com $\mathrm{HClO}_{4}$ e isto tem sido atribuído à adsorção de ânions sulfato competitivamente com o combustível. Contudo, o $\mathrm{HClO}_{4}$ dá condições para uma maior cobertura de adsorbatos, de modo que não há uma clara vantagem em usá-lo (45).

O uso de eletrólito alcalino traz algumas vantagens em relação ao meio ácido. Uma dessas vantagens é que outros metais passam a ser tão ativos quanto a platina. Outra vantagem é menor presença de venenos catalíticos provenientes dos intermediários da reação. Contudo, as desvantagens do meio básico envolvem: formação de carbonatos devido a retenção de $\mathrm{CO}_{2}$ pela solução. Conforme a solução retém $\mathrm{CO}_{2}, \mathrm{o} \mathrm{pH}$ diminui 
e a densidade de corrente diminui $(12,46,47)$. Levando em consideração a performance de uma célula a combustível constituída por eletrólito alcalino, misturas equimolares de combustível e base atinge as máximas densidades de corrente. Há evidências de que o $\mathrm{OH}^{-}$ realmente impede ou diminui a formação de espécies que atuam como veneno catalítico (48). O fato da taxa de oxidação, em meio alcalino, aumentar com o aumento do pH sugere que o $\mathrm{OH}^{-}$é doado da solução e não de espécies adsorvidas na superfície (12).

\subsubsection{Mecanismos de Reação}

As reações que ocorrem nos eletrodos são complicadas pela existência de etapas paralelas. A formação de adsorbatos, quando ocorrem por reações paralelas, podem ser um exemplo de reação paralela indesejada.

A oxidação de metanol para $\mathrm{CO}_{2}$ envolve $6 e^{-}$e a oxidação ocorre em várias etapas com vários produtos ou intermediários (40). Medidas realizadas com espectrômetro de massas mostrou que tanto $\mathrm{HCOH}$ quanto $\mathrm{HCOOH}$ são produzidos durante a oxidação de metanol sobre Pt em soluções ácidas (49). Similarmente, por cromatografia gasosa também detectou $\mathrm{HCOOCH}_{3}, \mathrm{CO}_{2}, \mathrm{HCOOH}$ e $\mathrm{HCOH}$ durante a oxidação do metanol em Pt em solução de $\mathrm{H}_{2} \mathrm{SO}_{4}(50)$.

A eletro-oxidação de moléculas orgânicas pequenas apresenta usualmente instabilidades dinâmicas que pertencem à classe de osciladores HN-NDR $(36,37,51,52)$. A denominação surge devido à presença de uma NDR, em uma curva de polarização na forma de "N" parcialmente escondida (hidden, H) em voltametria. A emergência de oscilações por meio de HN-NDR ocorre através da inserção de um grau a mais de liberdade ao sistema. Este grau de liberdade adicional corresponde ao um ciclo de retroalimentação negativo.

As instabilidade dinâmicas emergentes nas reações envolvendo moléculas orgânicas pequenas estão relacionadas com duas particularidades: (i) o mecanismo dual (1) no qual a molécula é diretamente oxidada a $\mathrm{CO}_{2}$ ou o eletrodo catalisa a formação de, no mínimo, um intermediário estável que será oxidado em valores mais altos de sobrepotencial. Este adsorbato irá atuar como veneno no mecanismo direto e, consequentemente, causará uma diminuição da corrente em baixos sobrepontenciais (37); (ii) a existência de competição por sítios livres da superfície do catalisador entre moléculas orgânicas e água. A ligação entre a água e o eletrodo torna-se mais intensa em maiores sobrepotenciais. A diminuição da disponibilidade de sítios livres para oxidar as moléculas orgânicas na via direta em maiores sobrepotenciais dá origem à N-NDR, justamente por causa da característica (ii). Assim, a corrente de oxidação diminuirá com o aumento do sobrepotencial. A via indireta, por sua vez, suprime a oxidação direta em valores baixos de sobrepotencial.

A eletro-oxidação de ácido fórmico é considerada uma reação modelo para estudos cinéticos $(53,54)$, isto porque apresenta um mecanismo de oxidação relativamente simples quando comparado com formaldeído, metanol e etanol, por exemplo. O meca- 
nismo de eletro-oxidação do ácido fórmico através de duas vias paralelas (55-58) tem grande aceitação na literatura. Contudo, uma terceira via tem sido discutida recentemente. Nesta, o íon formiato é formado em solução devido ao equilíbrio ácido-base e, assim, produz uma espécie que oxida a $\mathrm{CO}_{2}(59)$.

Em contrapartida, o metanol apresenta um mecanismo de maior complexidade, devido ao maior número etapas e de intermediários que são formados no processo, mas como o ácido fórmico e a maioria das moléculas orgânicas pequenas, a eletro-oxidação procede através de duas vias paralelas(1):

Figura 4 - Esquema simplificado da oxidação de metanol mostrando duas vias reacionais paralelas. (1).

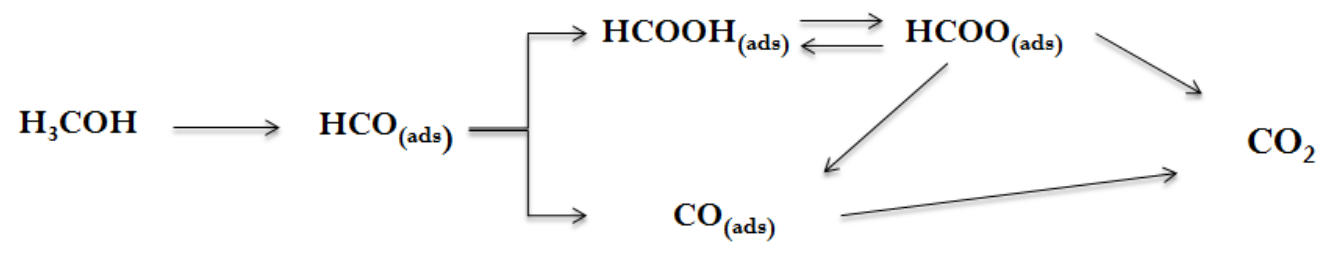

Resumidamente, o processo indireto, que envolve a formação de monóxido de carbono adsorvido na superfície, ocorre passando por várias etapas de desidrogenação (60). Por outro lado, as espécies solúveis formadas (formaldeído ou ácido fórmico), oxidam-se a $\mathrm{CO}_{2}$ na via direta.

O processo de eletro-oxidação de moléculas orgânicas pequenas está sujeito a convergir para um regime oscilatório, em que podem ser obtidas tanto oscilações de corrente como de potencial, dependendo das condições experimentais. Martins e colaboradores (61) mapearam a região em que é possível encontrar oscilações de corrente durante a eletrooxidação de metanol usando um diagrama de bifurcação ou diagrama de fase no plano $U$ vs. $R_{s}$. Neste diagrama, a situção em que a voltagem e a resistência tendem ao infinito está relacionada com o controle galvanostático. Em 2010, Boscheto et al. (62) estudaram a eletro-oxidação oscilatória de metanol em platina usando a técnica de Espectroscopia de Absorção no Infravermelho Realçada pela Superfície (SEIRAS, do inglês Surface Enhanced InfraRed Absorption Spectroscopy) e confirmaram que o CO foi a principal espécie adsorvida durante o período de indução e também dentro do próprio regime oscilatório. Foi possível verificar que a frequência de vibração do CO linearmente adsorvido oscila em fase com o potencial de eletrodo e apresenta pequena amplitude. Os autores também obtiveram valores para o recobrimento de CO durante as oscilações de potencial em modo galvanostático, em que a densidade de corrente aplicada foi de $0,18 \mathrm{~mA} \mathrm{~cm}^{-2}$. Neste caso, a cobertura de CO na superfície apresenta um valor médio de aproximadamente $25 \%$ de uma monocamada, variando muito pouco durante as oscilações.

Já está bem estabelecido na literatura que a eletro-oxidação de moléculas orgânicas pequenas acontece através do mecanismo de via dupla, onde duas reações paralelas ocorrem simultaneamente. Na via direta a formação de um itermediário ativo de vida curta 
imediatamente converte-se a $\mathrm{CO}_{2}$. Na via indireta, ocorre o envenenamento do catalisador com moléculas de $\mathrm{CO}$ que é apenas oxidado em altos sobrepotenciais por espécies oxigenadas, como a água que adsorve na superfície. Mecanisticamente, as oscilações podem ser explicadas em termos dos ciclos de retroalimentação positivo e negativo. No positivo, o autocatalítico, a rápida adsorção de espécies oxigenadas leva ao aumento do potencial do eletrodo, enquanto o ciclo negativo é causado pela lenta adsorção de monóxido de carbono em baixos potenciais (37).

Em geral, grande quantidade dos estudos são conduzidos em meio ácido, no entanto, algumas vantagens são observadas quando os experimentos são executados em meio alcalino, como por exemplo, atividade catalítica de outros metais além da Pt, ausência de envenenamento do eletrodo por intermediários da reação (12). Entretanto, Strmcnik et al. (63) mostram que a oxidação de metanol em superfícies de platina é afetada, em meio alcalino, pela formação de clusters do tipo $\mathrm{OH}_{\mathrm{ad}}-\mathrm{M}^{+}\left(\mathrm{H}_{2} \mathrm{O}\right)_{\mathrm{x}}$ na superfície do eletrodo, em que $\mathrm{M}^{+}$corresponde aos cátions de metais alcalinos $\left(\mathrm{Li}^{+}, \mathrm{Na}^{+}, \mathrm{K}^{+}\right.$e $\left.\mathrm{Cs}^{+}\right)$. Essas interações não covalentes entre o metal hidratado e o grupo hidroxila adsorvido na superfície aumentam conforme a energia de hidratação do metal. O que se observa é que quanto mais forte essas interações menor é a taxa de oxidação do metanol sobre platina. Assim, isto sugere que estes clusters bloqueiam os sítios ativos da platina para as reações eletrocatalíticas, e, ainda, concluem que o controle da natureza e da concentração de cátions de metais alcalinos podem servir como um novo parâmetro de ajuste para as reações de eletrocatálise.

A oxidação do formaldeído também já foi relatada com ocorrendo em várias etapas. A oxidação de $\mathrm{HCOH}$ para $\mathrm{HCOO}^{-}$envolve 2 elétrons no processo. Já foi evidenciado que as espécies adsorvidas na oxidação do formaldeído podem reagir para formar $\mathrm{CO}_{2}$ diretamente ou formar ácido fórmico o qual pode então dar origem ao dióxido de carbono ou venenos catalíticos (64).

\subsection{A Técnica de Nanobalança Eletroquímica de Cristal de Quartzo}

A região de interface eletrodo/solução, como já mencionado, apresenta características fundamentais para o entendimento dos processos de transferência de carga. Assim, entender como acontecem as variações de carga e massa nesta região torna-se crucial para averiguar como estes parâmetros relacionam-se com os fenômenos eletródicos. A técnica de nanogravimetria in situ com nanobalança eletroquímica a cristal de quartzo (NECQ) ganhou grande prestígio dentre aquelas usadas em eletroquímica por ser uma ferramenta potente no que diz respeito ao monitoramento de pequenas variações de massa superficial durante processos eletroquímicos, destacando-se também por ser considerada uma técnica custo relativamente baixo (65-67).

Inicialmente, a microbalança de cristal de quartzo (MCQ) foi utilizada como uma 
técnica ex situ para medir a massa de metais eletrodepositados (68). Posteriormente, quando uma face do cristal passou a ser utilizada como eletrodo de trabalho, em contato com a solução eletrolítica, para investigação de filmes finos sobre eletrodos (22), sendo então uma técnica in situ, a MCQ passou a ser denominada de microbalança eletroquímica de cristal de quartzo (MECQ). A nomenclatura NECQ só passou a utilizada mais recentemente, fazendo jus ao limite de detecção da técnica que é na escala de nanogramas.

O princípio fundamental de operação da NECQ encontra-se na piezoeletricidade. O efeito piezoelétrico foi investigado por Jacques e Pierre Curie no ano de 1880. Eles constataram que a aplicação de uma pressão externa sobre a superfície de alguns cristais, ou quando estes são submetidos a deformações, são capazes de gerar um campo elétrico cuja magnitude é proporcional à força aplicada (69). Em contrapartida, estes cristais sob a ação de um campo elétrico podem sofrer uma deformação, o efeito piezoelétrico reverso. Assim, por meio de uma perturbação elétrica adequada, em termos de amplitude e frequência, que são determinadas pelas características intrínsecas do cristal, fará com que este oscile mecanicamente em modo ressonante (70). Em outras palavras, o cristal pode oscilar em seu modo de cisalhamento. Os cristais de quartzo mais usados na NECQ são aqueles com o tipo de corte AT, devido ao baixo coeficiente de dependência com a temperatura.

Os cristais que atuam como o "coração" da NECQ apresentam formato de disco com depósito metálicos (e.g. ouro ou platina) em ambas as faces, onde o campo elétrico é aplicado. O movimento de vibração causado por este campo elétrico resulta em uma onda acústica que viaja transversalmente pelo cristal e apresenta uma frequência que está relacionada com a espessura do próprio cristal $\left(t_{q}\right)(65)$, como mostra a equação a seguir:

$$
f_{0}=\frac{v_{t r}}{t_{q}}=\frac{\left(\mu_{q}\right)^{1 / 2}}{2 t_{q}\left(\rho_{q}\right)^{1 / 2}},
$$

em que a constante 2 está relacionada com a condição de onda estacionária, ou seja, o comprimento de onda deve ser igual a $2 t_{q}, v_{t r}$ é a velocidade do som no cristal de quartzo de corte AT $\left(3,33 \times 10^{4} \mathrm{~m} / \mathrm{s}\right), \mu_{q}$ é o módulo de cisalhamento $\left(2,95 \times 10^{11} \mathrm{~g} \mathrm{~cm}^{-1} \mathrm{~s}^{-2}\right)$ e $\rho_{q}$ é a densidade do quartzo $\left(2,65 \mathrm{~g} \mathrm{~cm}^{-2}\right)$. Fica claro, deste modo, que a frequência de ressonância depende da espessura, estrutura atômica, forma e massa do cristal. Esta frequência pode sofrer variações quando ocorer uma adição ou subtração de massa ao cristal, e esta relação é descrita através da equação de Sauerbrey (71):

$$
\Delta f=-\frac{2 f_{0}^{2} \Delta m}{A\left(\mu_{q} \rho_{q}\right)^{1 / 2}}=-C_{f} \Delta m,
$$

em que $\Delta f$ é a variação de frequência de ressonância dada em $\mathrm{Hz}$, A é a área piezoeletricamente ativa em $\mathrm{cm}^{2}$, a qual apresenta é entre os filmes metálicos depositados em ambos os lados do cristal. Vale ressaltar que esta equação é válida dentro de certos limites, como 
por exemplo a deposição uniforme de um filme fino sobre a região ativa do ressonador $(70,71)$.

Uma representação elétrica equivalente pode ser idealizada para o ressonador de cristal de quartzo piezoelétrico quando todos os modos de vibração de ressonância indesejáveis puderem ser excluídos. Uma simples representação pode ser visualizada na Figura 5.

Figura 5 - Circuito elétrico equivalente para um ressonador de cristal de quartzo piezoelétrico.

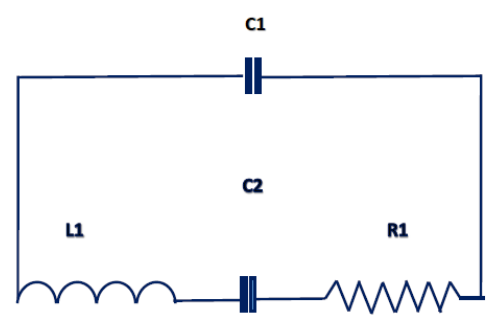

Pode-se notar que o sistema é composto de 4 elementos passivos, ou seja, uma resistência equivalente, $\mathrm{R}$, representando o elemento que dissipa energia, e três elementos que armazenam energia: dois capacitores representados por $\mathrm{C} 1$ e $\mathrm{C} 2$, sendo o primeiro relacionado com o armazenamento de energia durante as oscilações e o segundo que é a capacitância estática do ressonador de quartzo devido aos eletrodos, e o terceiro elemento em série, o indutor L1, é o componente relacionado com o deslocamento de massa devido às oscilações. Este modelo de circuito é comumente denominado de Butterworth-van Dyke equivalent circuit model (72). 


\section{Capítulo 3}

\section{OBJETIVOS}

O objetivo desta dissertação é acompanhar a variação de massa superficial utilizando a técnica de nanobalança eletroquímica de cristal de quartzo in situ durante a eletro-oxidação de metanol sobre platina, verificando as instabilidades cinéticas presentes nestes sistemas.

Especificamente, cada capítulo deste trabalho apresenta uma série de resultados que contribuem para que o objetivo final seja atingido. Desse forma, cada Capítulo traz um objetivo específico:

$\checkmark$ Capítulo 4 - Mostrar, com o auxílio da nanobalança eletroquímica de cristal de quartzo, o impacto dos cátions de metais alcalinos sobre a formação de óxido de platina e durante a oxidação de metanol;

$\checkmark$ Capítulo 5 - Monitorar a variação de massa superficial durante a formação de óxido de platina em meio ácido com diferentes ânions. Calcular o recobrimento de CO durante a eletro-oxidação oscilatória de metanol;

$\checkmark$ Capítulo 6 -Estimar o recobrimento do óxido de platina e de CO durante o transiente de circuito aberto para o sistema de metanol em meio ácido e alcalino. 


\section{Capítulo 4}

\section{Eletro-Oxidação de Metanol em Meio Alcalino}

\subsection{Procedimento Experimental}

Os experimentos foram conduzidos por meio de medidas de voltametria cíclica e nanogravimetria. Utilizou-se eletrólitos aquosos contendo KOH (99,99\%, Sigma Aldrich) e $\mathrm{LiOH}$ (99,995\%, Alfa Aesar), ambos com concentração de 0,1 mol L ${ }^{-1}$ e, como combustível, $\mathrm{H}_{3} \mathrm{COH}(99,98$, Qhemis) na mesma concentração. Todas as soluções foram preparadas com água ultra-pura Mili-Q (Millipore 18,2 m $\Omega . c m$ ). Os experimentos foram realizados usando como referência o eletrodo reversível de hidrogênio (RHE), confeccionado com a mesma solução do eletrólito de suporte. O contra-eletrodo (CE) foi constituído do mesmo metal que o eletrodo de trabalho, no entanto com maior área superficial. O eletrodo de trabalho foi um cristal de quartzo de corte AT coberto com uma fina camada de metal, com área geométrica de $0,361 \mathrm{~cm}^{-2}$ e frequência fundamental de $6 \mathrm{MHz}$. Para converter a variação de frequência em variação de massa foi feita uma calibração por meio de uma cronoamperometria, de acordo com a referência (73), em que a constante para conversão utilizada na equação de Sauerbrey, equação (2.5), assume o valor de $9,2 \mathrm{ng} \mathrm{Hz}^{-1} \mathrm{~cm}^{-2}$.

Previamente a cada experimento, a vidraria utilizada foi imersa em uma solução de permanganato de potássio levemente alcalinizada por aproximadamente 12 horas. Posteriormente, a solução foi removida lavando-se com água ultrapura e solução levemente ácida de peróxido de hidrogênio. A vidraria ficou imersa por 20 minutos na solução de peróxido e em seguida esta foi removida e aquela lavada em água ultrapura, sendo em seguida aquecida até a ebulição. O procedimento de lavagem com água fervente foi repetido por três vezes. A limpeza do eletrodo de trabalho foi feita com água fervente. 
O contra eletrodo foi limpo utilizando-se de aquecimento em chama ao rubro. Após a finalização de todo esse procedimento a célula eletroquímica era montada e dado o início da limpeza eletroquímica. Esta consistia em 250 ciclos de voltametria a $500 \mathrm{mV} . \mathrm{s}^{-1}$ entre os potenciais de 0,05 e $1,5 \mathrm{~V}$.

Nos experimentos de eletro-oxidação, manteve-se fluxo Argônio dentro da célula por aproximadamente 30 minutos e em seguida foram realizados os 250 ciclos de voltametria, mantendo o fluxo de argônio (99,996\%, White Martins) no interior da célula, antes de iniciar as medidas. Este procedimento foi realizado com intuito de obter uma superfície de platina estável e reprodutível. As caracterizações eletroquímicas foram realizadas em potenciostato/galvanostato PGSTAT320N Autolab com módulo Scan-Gen. A frequência do ressonador de quartzo é controlada por um módulo com resolução de $0,07 \mathrm{~Hz}$, neste equipamento.

\subsection{Resultados e Discussão}

4.2.1 Diferenças no voltamograma base e na nanogravimetria entre soluções contendo $\mathrm{KOH}$ e $\mathrm{LiOH}$

A Figura 6 mostra os resultados obtidos para $0,1 \mathrm{M}$ de $\mathrm{KOH}$ (curvas em preto) e $0,1 \mathrm{M}$ de $\mathrm{LiOH}$ (curvas em vermelho). Observa-se, como já mencionado na literatura (74), que o $\mathrm{Li}^{+}$, quando comparado com o $\mathrm{K}^{+}$, atua de modo a retardar o processo de formação de óxido sobre o eletrodo. Isto pode ser confirmado comparando a carga de oxidação nos dois casos, em que no caso do $\mathrm{Li}^{+}$, a densidade de carga para este processo é de $0,72 \mathrm{mC} \mathrm{cm}^{-2}$, enquanto que para o $\mathrm{K}^{+}$a mesma assume o valor de $0,78 \mathrm{mC} \mathrm{cm}^{-2}$, ou seja, a densidade de carga é 1,08 vezes maior no segundo caso.

$\mathrm{O}$ processo de oxidação da superfície tem início em $\sim 0,5 \mathrm{~V}$ (75). Na Figura 6.a, os picos em $\sim 0,65 \mathrm{~V}$ e 0,82 $\mathrm{V}$ estariam relacionados com a formação de PtOH através da adsorção reversível de $\mathrm{OH}^{-}$, processo que envolve apenas um elétron, de acordo com a referência (75). Contudo, em trabalhos posteriores esse processo foi aceito como a formação de $\mathrm{PtO}$ (39).

A análise dos dados fornecidos pela NECQ (Figura 6.b) adquiridos juntamente com a voltametria resultou nas seguintes observações: (i) a variação de massa $(\delta \Delta \mathrm{m}=$ $\left.\Delta \mathrm{m}_{2}-\Delta \mathrm{m}_{1}\right)$ entre o início da adsorção reversível de espécies oxigenadas até o potencial limite, ou seja entre $\sim 0,5-1,3 \mathrm{~V}$ é $\delta \Delta \mathrm{m}=44,3 \mathrm{ng} \mathrm{cm}^{-2}$ e $40,8 \mathrm{ng} \mathrm{cm}^{-2}$ para as soluções de $\mathrm{KOH}$ e $\mathrm{LiOH}$, respectivamente ; (ii) a variação de massa na região de redução de óxido $(1,1-0,45 \mathrm{~V})$ é $\delta \Delta \mathrm{m}=41,6 \mathrm{ng} \mathrm{cm}^{-2}$ para $\mathrm{KOH}$ e $(1,1-0,42 \mathrm{~V})$ para o LiOH é $\delta \Delta \mathrm{m}=$ $42,4 \mathrm{ng} \mathrm{cm}^{-2}$. Por meio de integração do voltamograma cíclico obteve-se a variação de carga para um ciclo. A Figura 6.c mostra que a variação de carga durante a oxidação da superfície acontece de maneira praticamente linear conforme o valor de E aumenta, tanto para a solução de $\mathrm{KOH}$ quanto para a de $\mathrm{LiOH}$. De modo semelhante ao realizado com os 
Figura 6 - a) Perfil voltamétrico, b) variação de massa e c) da densidade de carga durante um ciclo de voltametria. Eletrólito: $0,1 \mathrm{M}$ de $\mathrm{KOH}$ ou LiOH. Velocidade de varredura de $50 \mathrm{mV} \mathrm{s}^{-1}$.
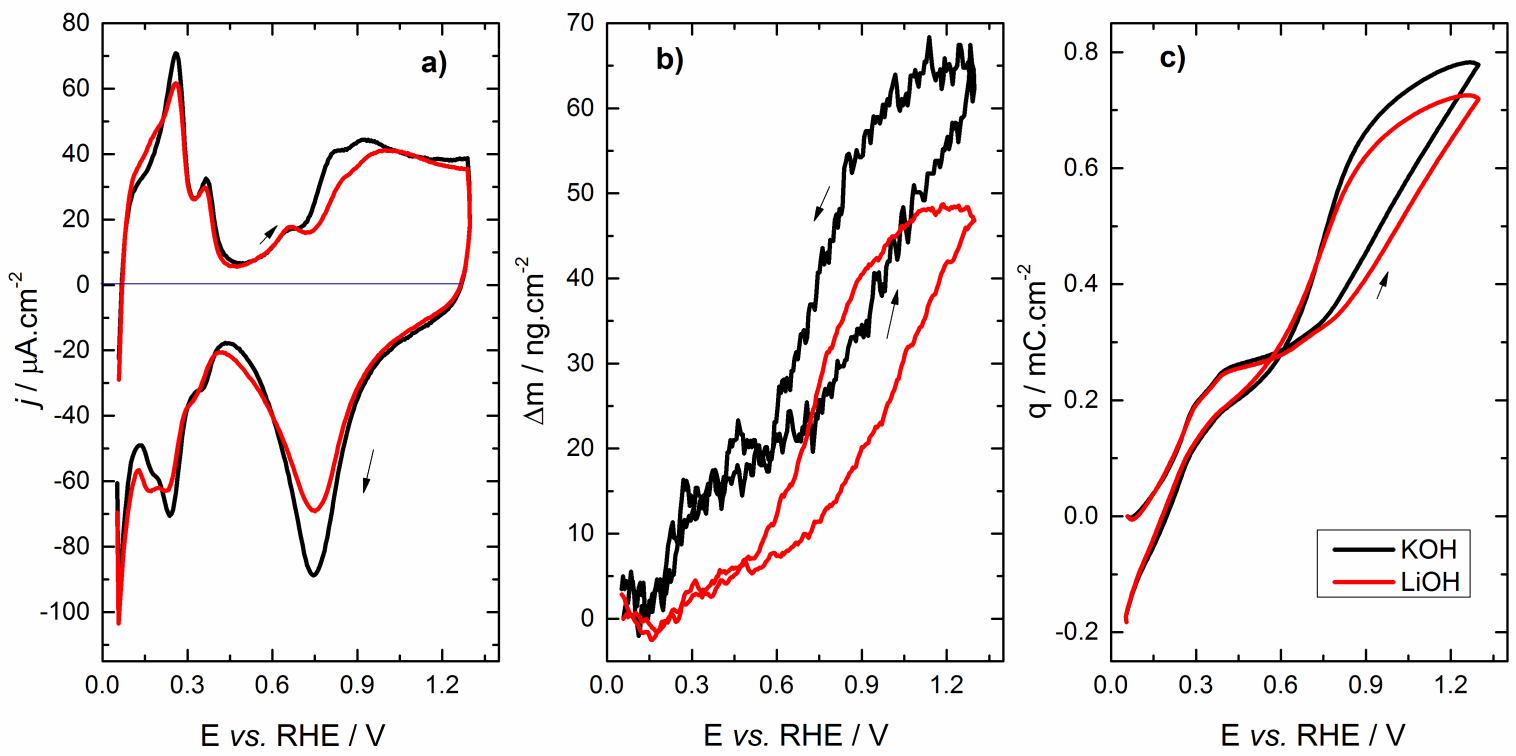

dados da NECQ, pôde ser obtido dados da variação de carga $\Delta$ q durante a oxidação da superfície. Para a solução de $\mathrm{KOH}, \Delta \mathrm{q}$ assume os valores de $0,56 \mathrm{mC} \mathrm{cm}^{-2}$ e para o caso contendo $\mathrm{LiOH}$ os valores de $\Delta \mathrm{q}$ para formação da camada de óxido é $0,48 \mathrm{mC} \mathrm{cm}^{-2}$.

A determinação da massa molar $(M)$ da cobertura de óxido sobre a superfície de platina é feita utilizando a Lei de Faraday:

$$
\delta \Delta \mathrm{m}=\frac{\Delta \mathrm{q} M}{n F}
$$

em que $\delta \Delta \mathrm{m}$ é a variação de massa, obtida com a NECQ, entre os dois limites de potencial como já mencionado anteriormente, $\Delta \mathrm{q}$ é variação da densidade de carga associada ao processo de oxidação da superfície e foi obtido através de medidas voltamétricas, $n$ é o número de elétrons transferido durante o processo e $F$ é a constante de Faraday, cujo valor é $96.485 \mathrm{C} / \mathrm{mol}$. Para realização dos cálculos assumiu-se que a oxidação da superfície resulta em PtO dentro da faixa de potencial estudada $(39,75)$, ou seja, entre $0,5 \mathrm{~V}$ e 1,3 V formando $\mathrm{PtO}_{2}$ apenas em potenciais mais elevados. Assim, o número de elétrons transferidos, $n$, no processo foi considerado 2 e, obviamente, o estado de oxidação da Pt foi +2 . O valor de $M$ calculado para a formação de óxido na solução de $\mathrm{KOH}$ foi de $15,25 \mathrm{~g} \mathrm{~mol}^{-1}$ e para a solução de $\mathrm{LiOH}, 16,24 \mathrm{~g} \mathrm{~mol}^{-1}$. Observa-se que estes valores calculadas são muito próximos do valor esperado para a formação de uma monocamada (1 ML) de óxido, que corresponde a $16,0 \mathrm{~g} \mathrm{~mol}^{-1}$ (39). Para verificar a quantidade de monocamadas formadas, considerou-se a carga dessorção de uma monocamada de $\mathrm{H}_{\mathrm{ads}}$ como $210 \mu \mathrm{C} \mathrm{cm}^{-2}$ e, portanto, a carga relacionada com a formação de uma monocamada de $\mathrm{PtO}$ igual a $420 \mu \mathrm{C} \mathrm{cm}^{-2}$. O resultado obtido é ilustrado na Figura 7. 
Figura 7 - Variação do recobrimento de óxido sobre a superfície de platina em função do potencial para soluções de $\mathrm{KOH}$ e LiOH 0,1 M.

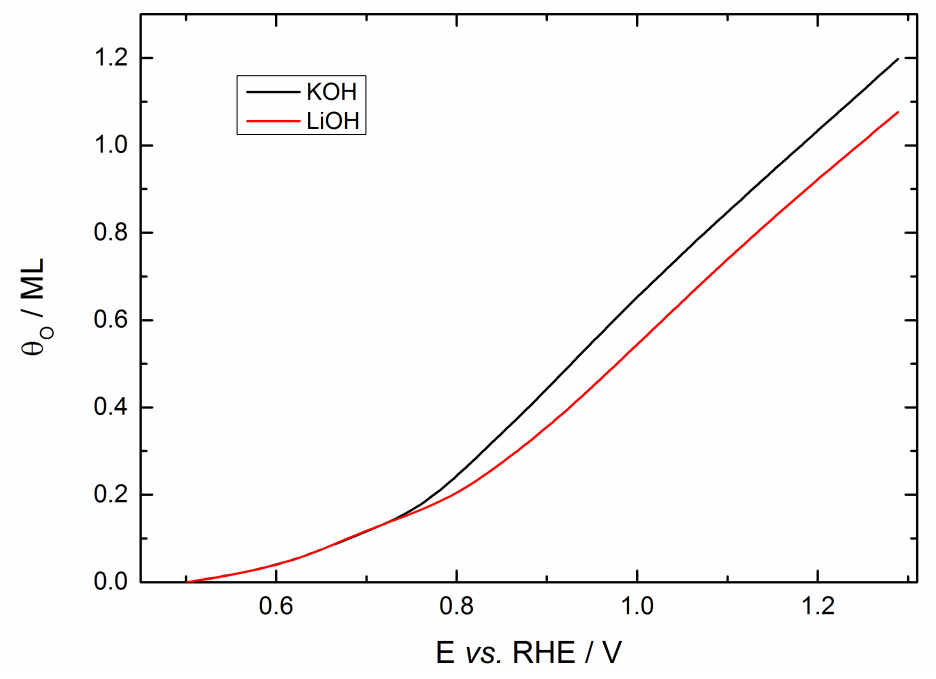

A oxidação da superfície pode ser afetada por fatores que envolvem certos tipos de interações denominadas de não covalentes. Estas, tiveram seu papel sobre a dupla camada elétrica e processos cinéticos desprezados durante muito tempo. Elas são caracterizadas pela presença de ligações de hidrogênio, ligações cátions-água e cátions-OH e aumentam de intensidade de acordo com a energia de hidratação do cátion $\left(\mathrm{Li}^{+}>>\mathrm{Na}^{+}>\mathrm{K}^{+}>\mathrm{Cs}^{+}\right)(63)$, que é inversamente proporcional ao raio do íon. Assim, os cátions de metais alcalinos $\left(\mathrm{M}^{+}\right)$ hidratados podem formar clusters com $\mathrm{OH}_{\text {ads }}$ do tipo $\mathrm{OH}_{\mathrm{ads}}-\mathrm{M}^{+}\left(\mathrm{H}_{2} \mathrm{O}\right)_{\mathrm{x}}$ na interface com o eletrodo e bloquear sítios que poderiam estar disponíveis para reagir. Consequentemente, pode-se sugerir que os cátions de alguma forma estão influenciando na maneira como inciase o processo de oxidação da superfície do eletrodo resultando em um maior recobrimento quando tem-se como eletrólito o $\mathrm{KOH}$, como mostra a Figura 7, sendo $\theta \sim 1,2$ e 1,1 para as soluções contendo $\mathrm{KOH}$ e $\mathrm{LiOH}$, respectivamente.

4.2.2 Variação de Massa durante a Eletro-Oxidação de Metanol em meio Alcalino: influência dos cátions $\mathrm{Li}^{+}$e $\mathrm{K}^{+}$

A eletro-oxidação completa de metanol em meio alcalino pode ser escrita como:

$$
\mathrm{CH}_{3} \mathrm{OH}+8 \mathrm{OH}^{-} \rightleftharpoons \mathrm{CO}_{3}^{2-}+6 \mathrm{H}_{2} \mathrm{O}+6 e^{-}
$$

Contudo, como mostra a Figura 4, este é um processo que envolve vários intermediários, o que torna esta reação mais complexa do que aparenta. Com o intuito de verificar a eletrooxidação de metanol em meio alcalino sob influência dos cátions $\mathrm{K}^{+}$e $\mathrm{Li}^{+}$foram utilizadas as técnicas de voltametria cíclica e nanogravimetria. Os resultados são mostrados na Figura 8.

Fica evidente que o processo é muito mais favorável na presença de $\mathrm{K}^{+}$do que de $\mathrm{Li}^{+}$. Em seu artigo publicado na revista Nature no ano de 2009, Markovic e colaboradores 
Figura 8 - a) Perfil Voltamétrico, b) Variação de massa e c) Variação da densidade de carga durante um ciclo de voltametria. Eletrólitos: 0,1 M de $\mathrm{KOH}$ ou $\mathrm{LiOH}$ e $0,1 \mathrm{M}$ de $\mathrm{H}_{3} \mathrm{COH}$. Velocidade de varredura de $50 \mathrm{mV} \mathrm{s}^{-1}$.
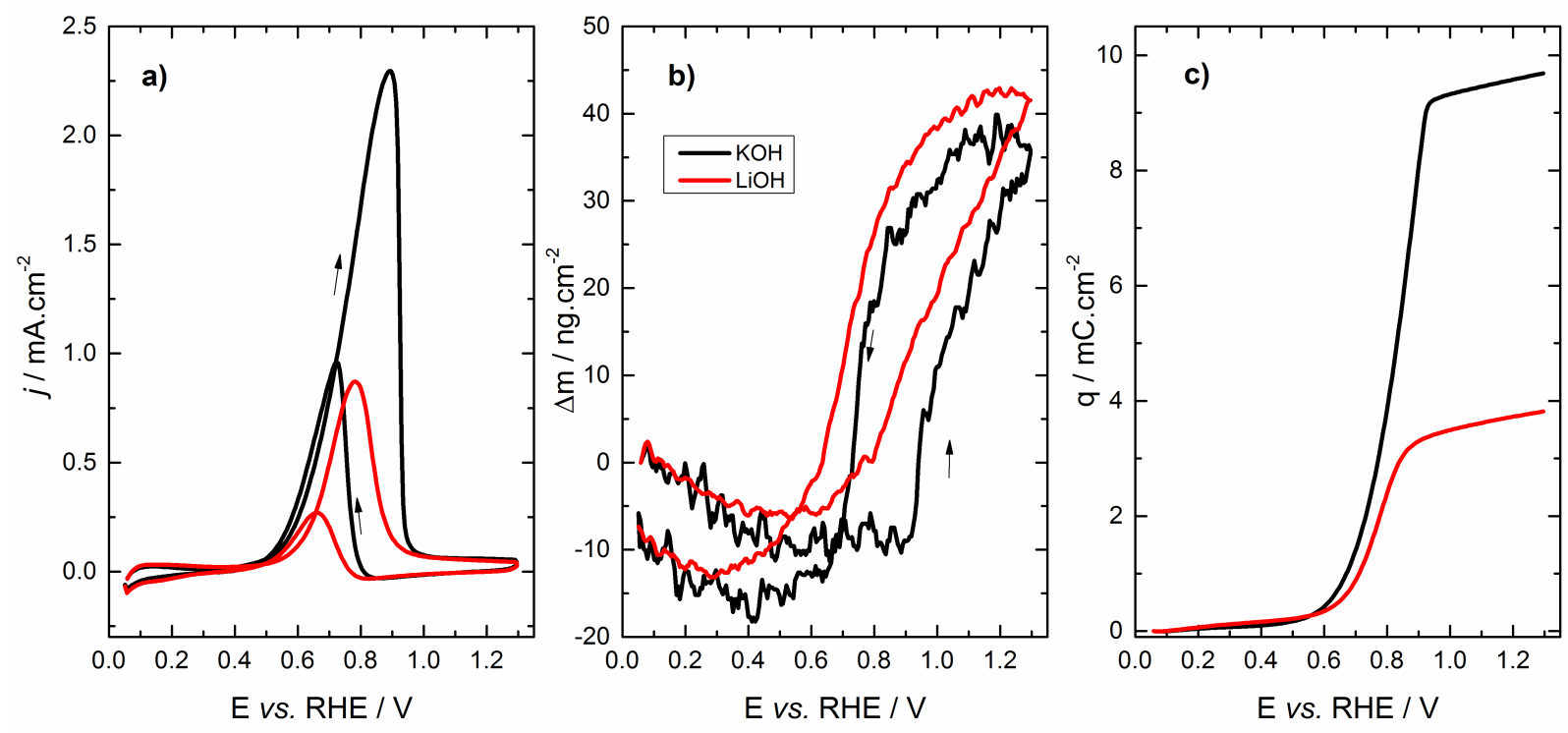

(63) utilizaram cálculos de DFT para sugerir que $\mathrm{Li}^{+}$interage muito mais fortemente com o $\mathrm{OH}_{\mathrm{ads}}$ do que os cátions menos hidratados, como o $\mathrm{K}^{+}$, assim, eles propuseram que a concentração de clusters do tipo $\mathrm{OH}_{\mathrm{ads}}-\mathrm{Li}^{+}\left(\mathrm{H}_{2} \mathrm{O}\right)_{\mathrm{x}}$ estariam em maior quantidade na superfície em relação àqueles envolvendo outro cátion de metal alcalino. Os resultados aqui expostos estão de acordo com o que foi relatado. Como pode ser observado (Figura 8.a), a densidade de corrente produzida durante a varredura positiva na situação em que se tem $\mathrm{KOH}$ como eletrólito é em torno de 2,6 vezes maior do que para o caso que se tem $\mathrm{LiOH}$. Algo semelhante também ocorre na varredura negativa de potencial, isto é, a densidade de corrente, neste caso, é aproximadamente 3,6 vezes maior para o mesmo sistema. Esse comportamento é refletido na variação de carga durante o processo oxidativo do combustível (Figura 8.c), obviamente, uma quantidade muito maior de carga é transferida na solução de KOH. Esses fenômenos são explicados, conforme a referência (63) considerando que aqueles clusters adsorvidos são apenas espectadores da reação, inibindo o movimento e a chegada de espécies reagentes sobre a superfície de platina. Como o cluster do tipo $\mathrm{OH}_{\mathrm{ads}}-\mathrm{Li}^{+}\left(\mathrm{H}_{2} \mathrm{O}\right)_{\mathrm{x}}$ apresenta maior energia de interação, é válido considerar que este apresenta um maior recobrimento sobre a superfície, reduzindo assim o número de sítios disponíveis para o processo eletrocatalítico.

Para melhor analisar os resultados obtidos com a NECQ na Figura 8.b apenas os dados durante a varredura no sentido positivo de potenciais foram plotados na Figura 9 para o caso do KOH e na Figura 10 para o caso do LiOH.

É possível verificar que, de acordo com a Figura 9, até o potencial que se atinge a máxima densidade de corrente para oxidação de metanol em $\mathrm{KOH}$ há uma diminuição de 
Figura 9 - Perfis de $j, \Delta \mathrm{m}$ e q durante a varredura no sentido positivo de potencial para a eletro-oxidação de $0,1 \mathrm{M}$ de metanol em $0,1 \mathrm{M}$ de $\mathrm{KOH} \cdot \mathrm{dE} / \mathrm{dt}=50 \mathrm{mV} \mathrm{s}^{-1}$

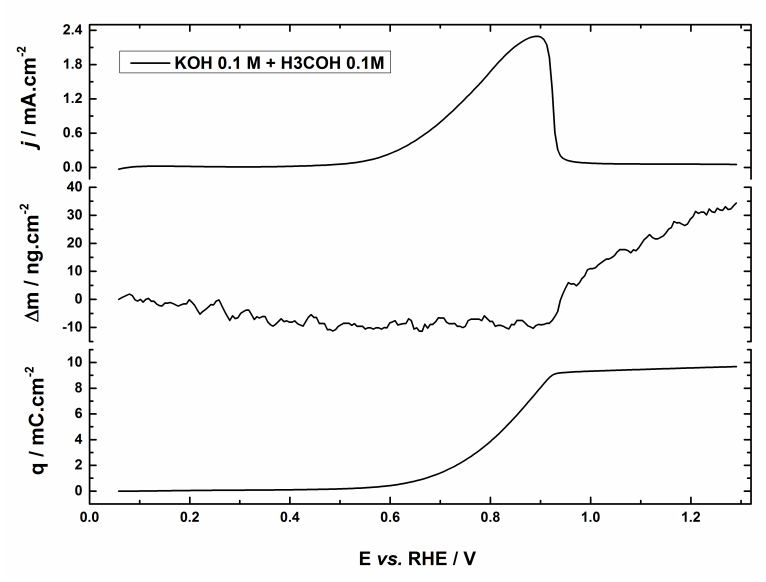

Figura 10 - Perfis de $j, \Delta \mathrm{m}$ e q durante a varredura no sentido positivo de potencial para a eletrooxidação de $0,1 \mathrm{M}$ de metanol em $0,1 \mathrm{M}$ de $\mathrm{LiOH}$. dE/dt = $50 \mathrm{mV} \mathrm{s}^{-1}$

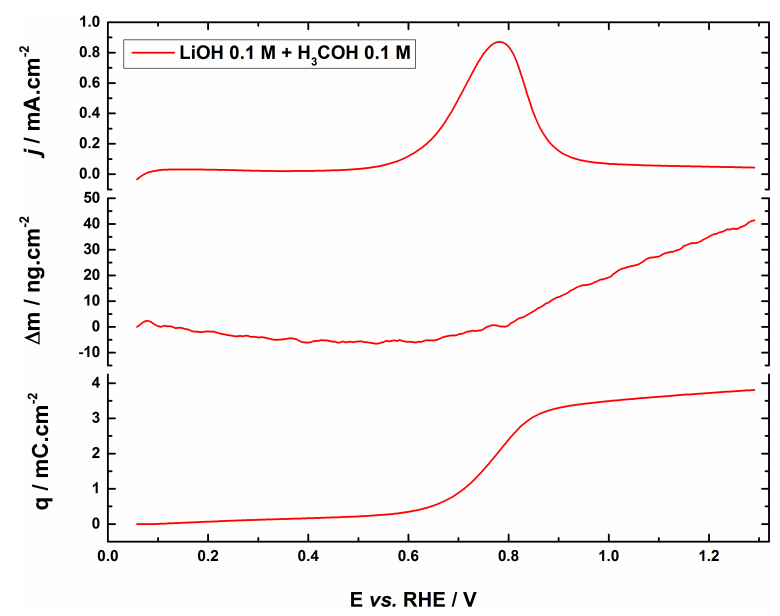

massa superficial. No ponto máximo de $j$, inicia-se um grande aumento de massa, por volta de $0,9 \mathrm{~V}$, e estende-se até o potencial limite, 1,3 V. Esse aumento de massa corresponde a $42,7 \mathrm{ng} \mathrm{cm}^{-2}$, no entanto, a diminuição de massa observada do começo do voltamograma até o potencial do pico da oxidação, $0,9 \mathrm{~V}$, é muito pequena, de apenas $8,5 \mathrm{ng} \mathrm{cm}^{-2}$, quando comparada com esse aumento mencionado. Por outro lado, considerando-se o sistema cujo eletrólito de base é o $\mathrm{LiOH}$, já é possível perceber um pequeno aumento de massa aproximadamente no início da oxidação do metanol, aumento este muito menos evidenciado do que aquele iniciado na região de máxima densidade de corrente. O primeiro ganho de massa corresponde a um valor de $5,5 \mathrm{ng} \mathrm{cm}^{-2}$, e o segundo em aproximadamente $0,8 \mathrm{~V}$ é de $41,3 \mathrm{ng} \mathrm{cm}^{-2}$, totalizando um aumento de massa de $46,8 \mathrm{ng} \mathrm{cm}^{-2}$. O acréscimo de massa que ocorre na parte final do voltamograma é, provavelmente, relacionado com a oxidação da superfície, e novamente pode-se observar a possível influência dos cátions $\mathrm{Li}^{+}$e $\mathrm{K}^{+}$em dois pontos relevantes: (i) a variação total de massa é maior para a solução contendo $\mathrm{LiOH}$ e (ii) esse aumento de massa é consideravelmente mais íngreme para o primeiro sistema em relação ao segundo.

\subsection{Conclusões do Capítulo}

Utilizando-se de solução de $\mathrm{KOH}$ ou LiOH, pôde-se perceber a influência exercida pelo cátion alcalino sobre a corrente de oxidação do metanol e a formação de óxido sobre a superfície de platina. $\mathrm{O}$ cátion $\mathrm{Li}^{+}$tem como propriedade uma maior energia de hidratação do que os demais cátions alcalinos e, consequentemente, atua bloqueando mais fortemente a superfície do eletrodo para que reações faradaicas possam ocorrer. Foi verificado que nas 
soluções contendo apenas os eletrólitos de base, $\mathrm{KOH}$ e $\mathrm{LiOH}$, a massa molar presente na superfície foi maior para a solução de $\mathrm{LiOH}$, e isso não significou que houvesse um maior recobrimento de óxido na superfície do eletrodo para este sistema. Diferentemente é o que ocorre para o processo de oxidação do metanol, em que a maior variação de massa é percebida no sistema cujo eletrólito de base é o KOH. Por fim, ressalta-se que a formação de óxido é foi mais favorecida utilizando-se a solução aquosa de hidróxido de potássio, e, possivelmente, a interação entre espécies oxigenadas, que se formam mais facilmente nesse caso, e os intermediários da reação de oxidação do metanol tem influenciado para a maior variação de massa verificada durante a eletro-oxidação do metanol em KOH aquoso. 


\section{Capítulo 5}

\section{Eletro-Oxidação de Metanol em Meio Ácido}

\subsection{Procedimento Experimental}

Os resultados apresentados nesse capítulo foram obtidos utilizando as técnicas de voltametria cíclica, cronopotenciometria e nanogravimetria. Foram investigados sistemas em meio ácido, utilizando eletrólito aquoso com $0,5 \mathrm{~mol} \mathrm{~L}{ }^{-1}$ de $\mathrm{H}_{2} \mathrm{SO}_{4}(97,98 \%$, J.T.Baker), 0,5 mol L ${ }^{-1}$ de $\mathrm{HClO}_{4}\left(70 \%\right.$, Nuclear) e $0,5 \mathrm{~mol} \mathrm{~L}{ }^{-1}$ de $\mathrm{HClO}_{4}+1,0^{-6} \mathrm{~mol} \mathrm{~L}^{-1}$ de $\mathrm{HCl}$ (37\%, Qhemis). O combustível orgânico estudado foi o $\mathrm{H}_{3} \mathrm{COH}$ (99,98, Qhemis) na concentração de $1 \mathrm{~mol} \mathrm{~L}^{-1}$ e $0,5 \mathrm{~mol} \mathrm{~L}^{-1}$, juntamente com os respectivos eletrólitos.

Os demais procedimentos utilizados nesse Capítulo são idênticos aos descritos no Capítulo 4 na seção 4.1, bem como as especificações técnicas.

\subsection{Metanol e Ácido Sulfúrico}

A Figura 11 mostra os resultados obtidos utilizando ácido sulfúrico aquoso como eletrólito de suporte para os sistemas com e sem metanol. A oxidação da superfície iniciase em aproximadamente $0,80 \mathrm{~V}$ e é acompanhada por um aumento de massa superficial de $62.4 \mathrm{ng} \mathrm{cm}^{-2}$ até $1,4 \mathrm{~V}$. Utilizando a relação $\mathrm{d} \delta \Delta \mathrm{m} / \Delta \mathrm{q}$ na equação (4.1), com o valor obtido para $\Delta$ q nessa faixa de pontencial é possível encontrar o valor de uma massa molar na superfície de $32,2 \mathrm{~g} \mathrm{~mol}^{-1}$, o que corresponderia a aproximadamente 2,0 monocamadas de óxido, considerando que a massa molar de uma monocamada de recobrimento por óxido seja de $16 \mathrm{~g} \mathrm{~mol}^{-1}$ (39). Cabe aqui ressaltar que este experimento foi realizado utilizando um eletrodo de trabalho com área ativa relativamente grande, de $1,1 \mathrm{~cm}^{2}$, com 
fator de rugosidade de 3,0. A área mencionada foi determinada por meio da densidade de carga associada à região de dessorção de hidrogênio, como mostra a referência (76).

Figura 11 - a) Perfil voltamétrico, b) variação de massa durante um ciclo de voltametria contendo apenas eletrólito; c) Perfil voltamétrico e d) variação de massa durante um ciclo de voltametria após a adição de 1,0 mol. $\mathrm{L}^{-1}$ de metanol . Eletrólito: 0,5 mol.L ${ }^{-1}$ de $\mathrm{H}_{2} \mathrm{SO}_{4}$. Velocidade de varredura: $50 \mathrm{mV} \mathrm{s}^{-1}$.

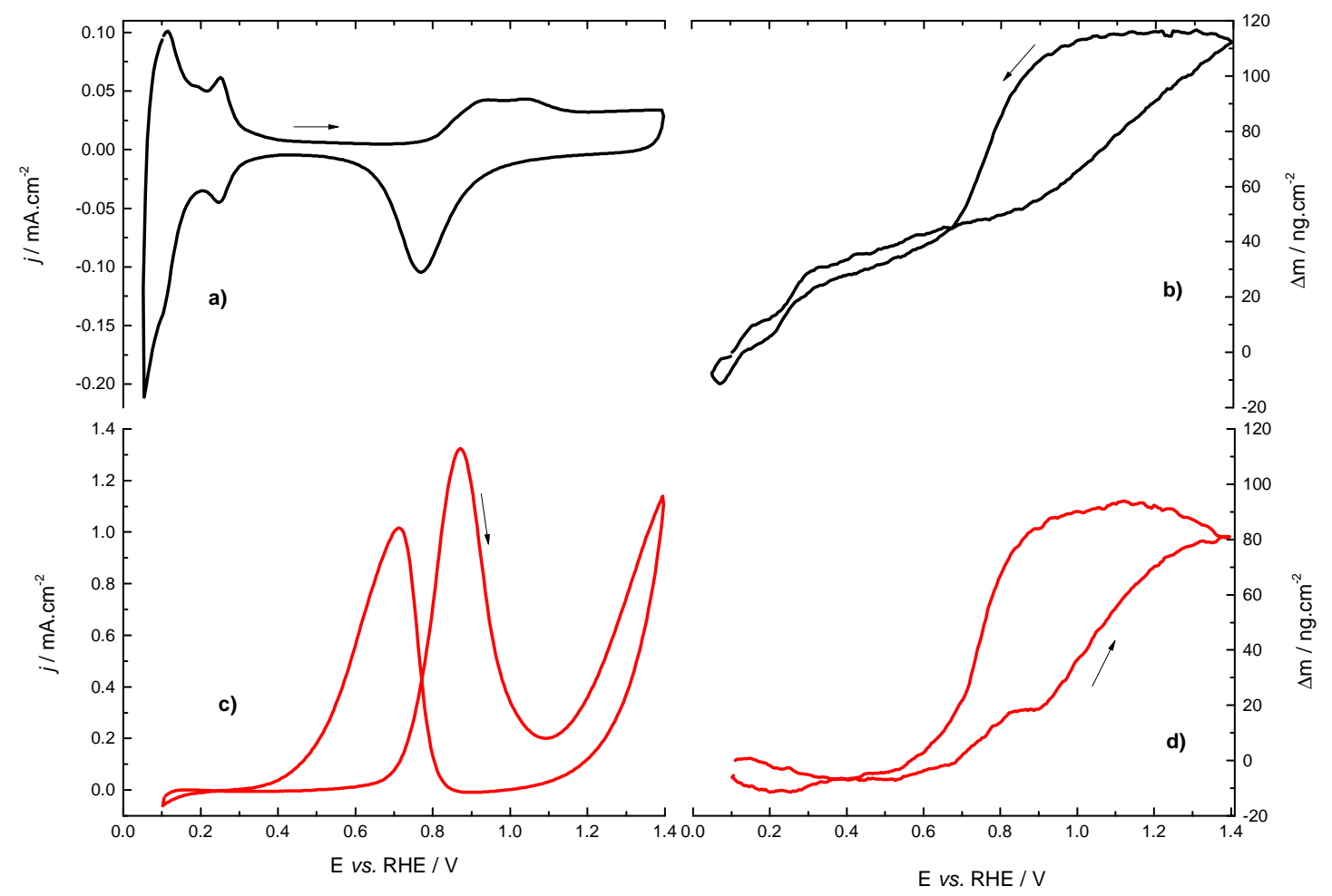

Para verificar esse valor, supostamente muito elevado para quantidade de monocamadas, foi construído com gráfico nos moldes da Figura 7 para o sistema em questão. A Figura 12 ilustra o resultado. É observado que o recobrimento por óxido na superfície é sutilmente maior que 0,9 no potencial de $1,4 \mathrm{~V}$. 
Figura 12 - Variação do recobrimento de óxido sobre a superfície de platina em função do potencial para $\mathrm{H}_{2} \mathrm{SO}_{4} 0,5 \mathrm{~mol} . \mathrm{L}^{-1}$

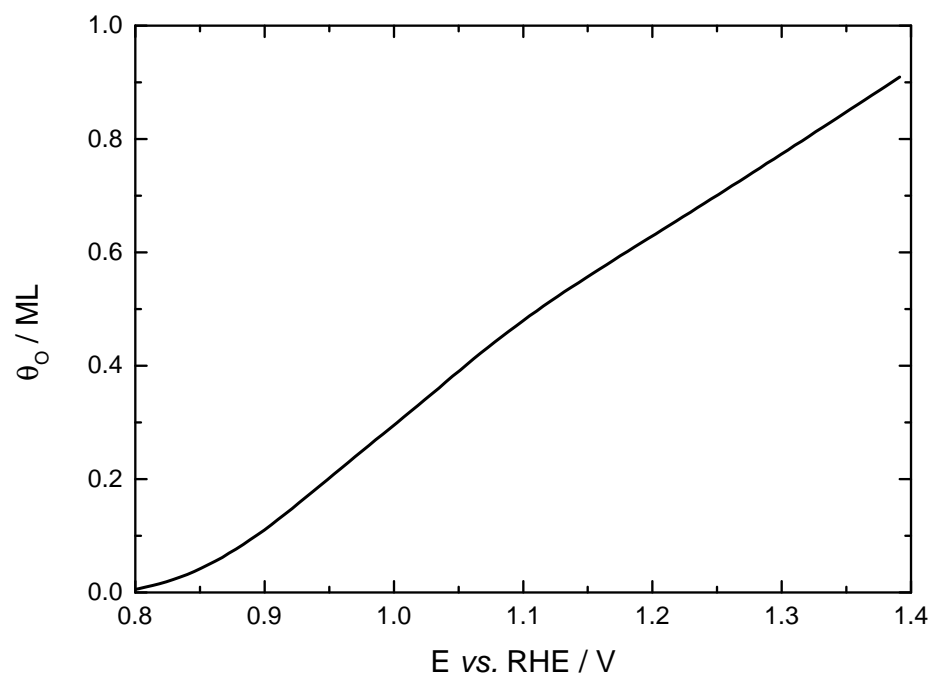

Após adicionar metanol, o perfil voltamétrico resultante e o de variação de massa são um tanto diferentes. Claramente, a região intermediária do voltamograma de platina e ácido sulfúrico, que contempla apenas as movimentações de cargas na dupla camada, já não se faz presente na Figura 11.

Nagao e colaboradores (1) mostraram pela primeira vez, com auxílio da técnica de espectrometria de massas eletroquímica diferencial (DEMS) on line e com simulações numéricas, as vias direta e indireta que levam ao produto final, $\mathrm{CO}_{2}$, durante a eletrooxidação oscilatória de metanol. Os autores mostraram que a produção de $\mathrm{CO}_{2}$ na via indireta, ou seja, via $\mathrm{CO}_{\text {ads }}$, encontra-se em fase com as oscilações de potencial em que o ponto máximo dos dois perfis coincidem. Já na via direta a maior produção de $\mathrm{CO}_{2}$ ocorre de maneira muito acentuada durante a diminuição do potencial e também coincide com a produção de HCO, que também já foi verificado como um intermediário da reação (77). Como já foi mostrado (62), aproximadamente $75 \%$ da superfície do eletrodo fica livre de $\mathrm{CO}$ e disponível para a adsorção e oxidação do metanol durante as oscilações. No entanto, mesmo com relativamente bastante espaço para este processo ocorrer, a variação de massa não apresenta valores tão significantes, como mostram os resultados expressos na Figura 13. Como a NECQ mede uma diferença de massa entre espécies que adsorvem e dessorvem na superfície, os resultados mostram que não há uma grande diferença entre essas massas durante as oscilações.

É possível estimar o valor da cobertura óxido $\left(\theta_{O}\right)$ na superfície para o experimento da Figura 11. Para isso, propõe-se a seguinte equação:

$$
\Delta m=\theta_{O} \cdot \Delta m_{M l P t O}-\theta_{C O} \cdot \Delta m_{M l P t C O}
$$

em que $\Delta m$ é a variação de massa obtida pela nanogravimetria, ou seja, $87,8 \mathrm{ng} . \mathrm{cm}^{-2}$, da região de baixo potencial onde se tem a maior quantidade de CO (aproximadamente 
$0,4 \mathrm{~V}$ ) até o potencial máximo, $1,4 \mathrm{~V} ; \theta_{C O}$ é recobrimento de $\mathrm{CO}$ em baixos potenciais cujo valor atribuído é $0.75 ; \Delta m_{M l P t C O}$ é a variação de massa para uma monocamada de CO que corresponde ao valor numérico estimado de $61,0 \mathrm{ng} . \mathrm{cm}^{-2}$; e $\Delta m_{M l P t O}$ é a variação de massa para uma camada de oxigênio sobre a platina, cujo valor é $34,9 \mathrm{ng} . \mathrm{cm}^{-2}$. Os valores de $\Delta m_{M l P t C O}$ e $\Delta m_{M l P t O}$ foram calculados considerando que $1 \mathrm{ML}$ de $\mathrm{CO}$ e $1 \mathrm{ML}$ de $\mathrm{O}$ têm massa de 28,0 g. $\mathrm{mol}^{-1}$ e 16,0 g.mol ${ }^{-1}$, respectivamente. Tendo em mãos estes valores juntamente com o valor da densidade superficial de mols de Pt, que é $2,18 \mathrm{nmol}_{\mathrm{cm}} \mathrm{cm}^{2}$ é possível chegar ao valores de massa utilizados na equação (5.1). Substituindo os valores nesta equação, chega-se ao valor de 3,8 para $\theta_{O}$.

Figura 13 - Oscilações de potencial (em preto) e massa (em vermelho) para o sistema composto de $0,5 \mathrm{~mol} \mathrm{~L}^{-1}$ de $\mathrm{H}_{2} \mathrm{SO}_{4}$ e $1 \mathrm{~mol} \mathrm{~L}^{-1}$ de $\mathrm{H}_{3} \mathrm{COH} . j=0,314 \mathrm{~mA} \mathrm{~cm}^{-2}$.

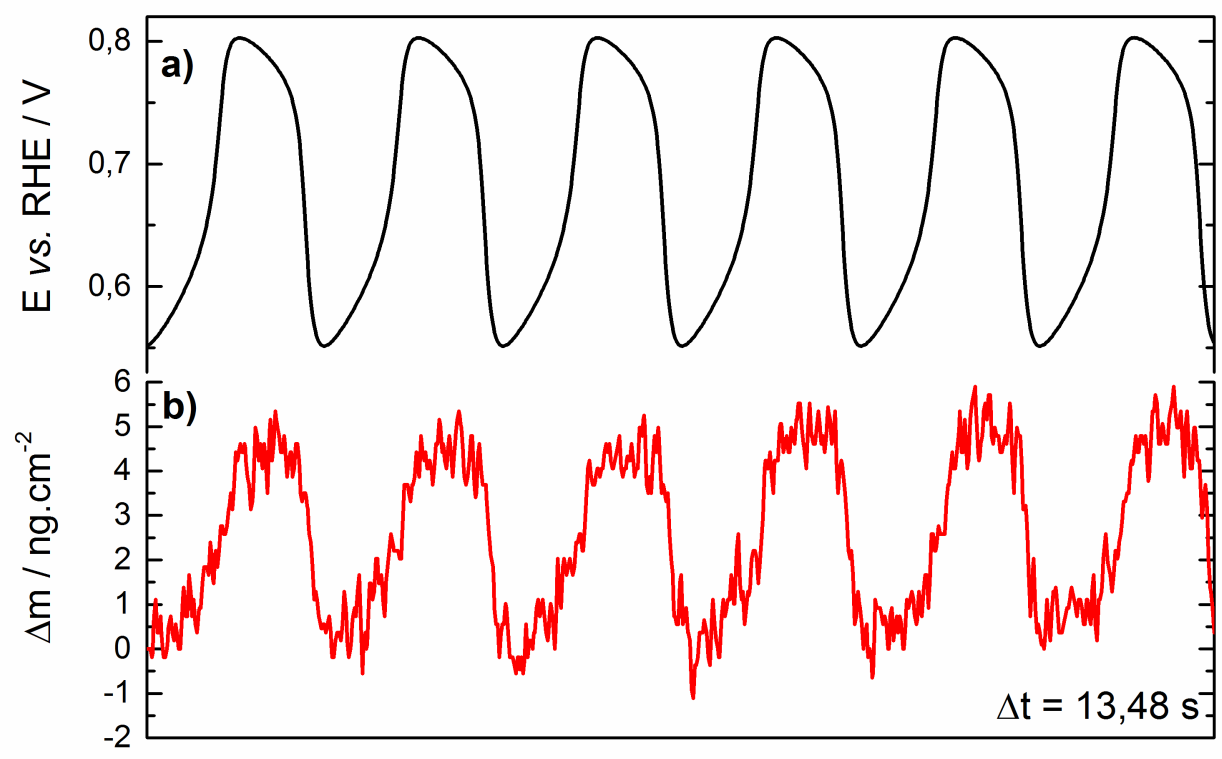

O que se observa da Figura 13 é: quando o potencial está em seu ponto máximo, a variação de massa o acompanha, e atinge o seu ponto máximo também. A varição de massa está localizada numa região que fica à margem da precisão com que a NECQ pode detectar a variação de frequência. De acordo com o dados técnicos do equipamento, a acurácia é de $1 \mathrm{~Hz}\left(9,2 \mathrm{ng} \mathrm{cm}^{-2}\right)$. Logo, torna-se difícil atribuir qual ou quais espécies especificamente são responsáveis por esta variação de massa. Não obstante, os dados da NECQ colaboram para comprovar que, no instante em que o potencial é máximo por encontrar-se a superfície recoberta por uma maior quantidade de espécies oxigenadas, a variação de massa atinge o valor máximo de aproximadamente $4,7 \mathrm{ng} \mathrm{cm}{ }^{-2}$ e diminui, com a diminuição do potencial, para as proximidades de seu valor inicial.

É possível estimar matematicamente o valor da variação da cobertura monóxido de carbono $\left(\Delta \theta_{C O}\right)$ na superfície durante as oscilações. Para isso, faz-se o uso da equação 
abaixo:

$$
\Delta m=\Delta \theta_{C O} \cdot m_{M L C O}
$$

considerando o valor de $\Delta m 4,7 \mathrm{ng} . \mathrm{cm}^{-2}$, chega-se ao valor, muito baixo, da variação da cobertura de CO durante as oscilações de 0,08.

\subsection{Metanol e Ácido Perclórico}

A influência da água e de diferentes tipos de ânion no perfil voltamétrico da platina policristalina já foi estudada por diversos autores (27,78-80). Um estudo mais detalhado envolve o acompanhamento da variação de massa da superfície do eletrodo juntamente com a voltametria cíclica, que pode ser feito com o auxílio da Nanobalança eletroquímica de cristal de quartzo. Um estudo conduzido por pesquisadores da Universidade de São Paulo do Instituto de Química de São Carlos (27) mostrou ser possível medir os valores da cobertura de diferentes ânions na superfície do eletrodo utilizando voltametria cíclica e nanogravimetria, cujos os valores observados foram de $7 \%$ para o perclorato e $19 \%$ para o fosfato.

5.3.1 Influência de $\mathrm{ClO}_{4}^{-}$e $\mathrm{Cl}^{-}$na formação de $\mathrm{PtO}$ e durante a eletro-oxidação de metanol

O perfil voltamétrico para $0.5 \mathrm{~mol} . \mathrm{L}^{-1}$ de $\mathrm{HClO}_{4}$ e após a adição de 1 mol.L ${ }^{-1}$ de metanol é mostrado na Figura 14. Com exceção dos experimentos realizados com $\mathrm{HCl}$, a região do voltamograma e da nanogravimetria até aproximadamente $0,4 \mathrm{~V}$ corresponde à dessorção de $210 \mu \mathrm{C} . \mathrm{cm}^{-2}$ de $\mathrm{H}_{a d s}$ e região associada ao potencial de aproximadamente 0,76 V define o início do processo de oxidação da superfície de platina. Assim, a variação de massa observada a partir de $0,76 \mathrm{~V}$ diz respeito à oxidação da superfície do catalisador, enquanto na varredura na direção contrária é associada à redução do óxido formado e à dessorção de ânions da superfície (78). No tocante às oscilações, Koper, Hachkar e Beden (10) utilizam a voltametria cíclica juntamente com a nanogravimentria para estudar o processo de eletro-oxidação oscilatória do formaldeído em eletrodos de platina e ródio em meio ácido e alcalino. Os autores puderam encontrar oscilações apenas em meio ácido. Além disso, concluíram que a nanobalança foi de crucial importância para demonstrar a influência da formação da camada de óxido sobre as oscilações.

A variação de massa observada em $1,4 \mathrm{~V}$ para a Figura $14 . b$ é de 84,8 ng.cm ${ }^{-2}$ e no potencial, após a adição de metanol, o valor para a variação de massa torna-se 59,6 ng. $\mathrm{cm}^{-2}$ na Figura 14.d. Com os resultados das medidas nanogravimétricas é possível fazer uma estimativa a respeito da massa de PtO que é formado durante a varredura positiva de potencial na voltametria após adição de metanol, com intuito quantificar a 
Figura 14 - a) Perfil voltamétrico, b) variação de massa durante um ciclo de voltametria contendo apenas eletrólito; c) Perfil voltamétrico e d) variação de massa durante um ciclo de voltametria após a adição de $1,0 \mathrm{~mol} \cdot \mathrm{L}^{-1}$ de metanol . Eletrólito: $0,5 \mathrm{~mol} . \mathrm{L}^{-1}$ de $\mathrm{HClO}_{4}$. Velocidade de varredura: $50 \mathrm{mV} \mathrm{s}^{-1}$.

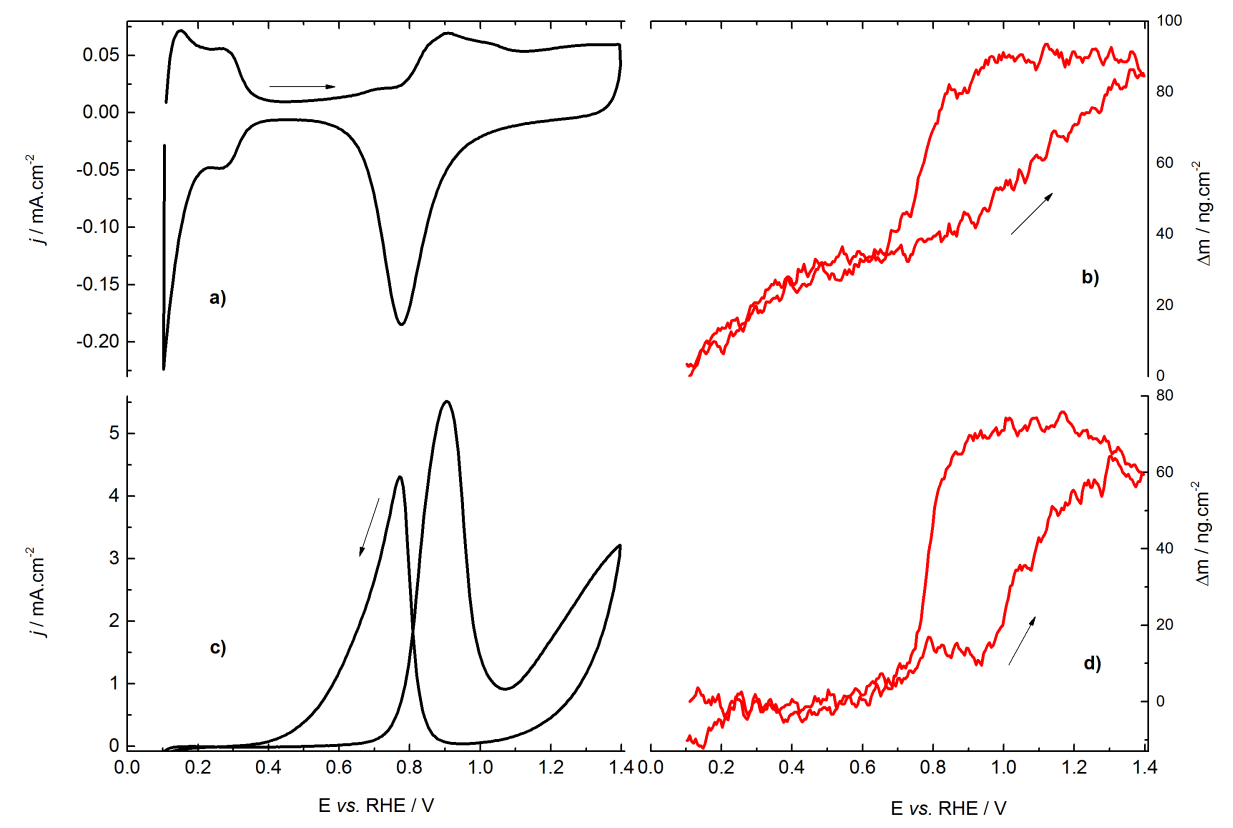

formação de óxido na superfície do eletrodo e posteriormente comparar este valor com aquele que será apresentado mais adiante durante as oscilações.

Para estimar o valor da cobertura óxido $\left(\theta_{O}\right)$ na superfície faz-se uso da equação (5.1). Neste caso, $\Delta m$ é assume o valor de 59,6 ng.cm ${ }^{-2}$; para as demais variáveis, os valores assumidos foram os mesmos apresentados na seção section 5.2. Substituindo os valores nesta equação, chega-se ao valor de 3,10 para $\theta_{O}$.

$\mathrm{O}$ sistema $\mathrm{HClO}_{4}+\mathrm{H}_{3} \mathrm{COH}$ apresenta oscilações de potencial em determinada faixa de corrente aplicada. O processo de eletro-oxidação do metanol em meio ácido é composto por diversas etapas com a formação de vários intermediários (1). O CO adsorvido na superfície tem papel fundamental para o surgimento das oscilações (81). A Figura 15 mostra em (a) o padrão formado pelas oscilações de potencial e em (b) o padrão formado pelas oscilações de massa na superfície do eletrodo para 1,0 mol.L $\mathrm{L}^{-1}$ de $\mathrm{H}_{3} \mathrm{COH}$ em 0,5 mol.L ${ }^{-1}$ de $\mathrm{HClO}_{4}$.

Utilizando a equação (5.2) e os dados obtidos da Figura 15 (b) pode-se determinar qual é a variação da cobertura de CO durante um período de oscilação. Assim, considerando $\Delta m$ igual a $4,9 \mathrm{ng} . \mathrm{cm}^{-2}$ chega-se a um $\Delta \theta_{C O}$ aproximadamente igual a 0,08 . Este valor é bem próximo do valor mostrado na referência (62), que é 0,05 aproximadamente.

A fim de verificar como pode ser afetada a eletro-oxidação de metanol quando há uma espécie que interage fortemente com o catalisador por meio de adsorção, foi introduzido no sistema ácido perclórico-metanol um pequeno volume de ácido clorídrico, de modo que a concentração de $\mathrm{Cl}^{-}$fosse de $10^{-6}$ mol.L $\mathrm{L}^{-1}$. A corrente de oxidação do 
Figura 15 - Oscilações de potencial (a) e massa (b) para o sistema com 0,5 mol. $\mathrm{L}^{-1}$ de $\mathrm{HClO}_{4}$ e 1,0 mol.L $\mathrm{L}^{-1}$ de metanol. $\mathrm{i}=0,49 \mathrm{~mA}$.

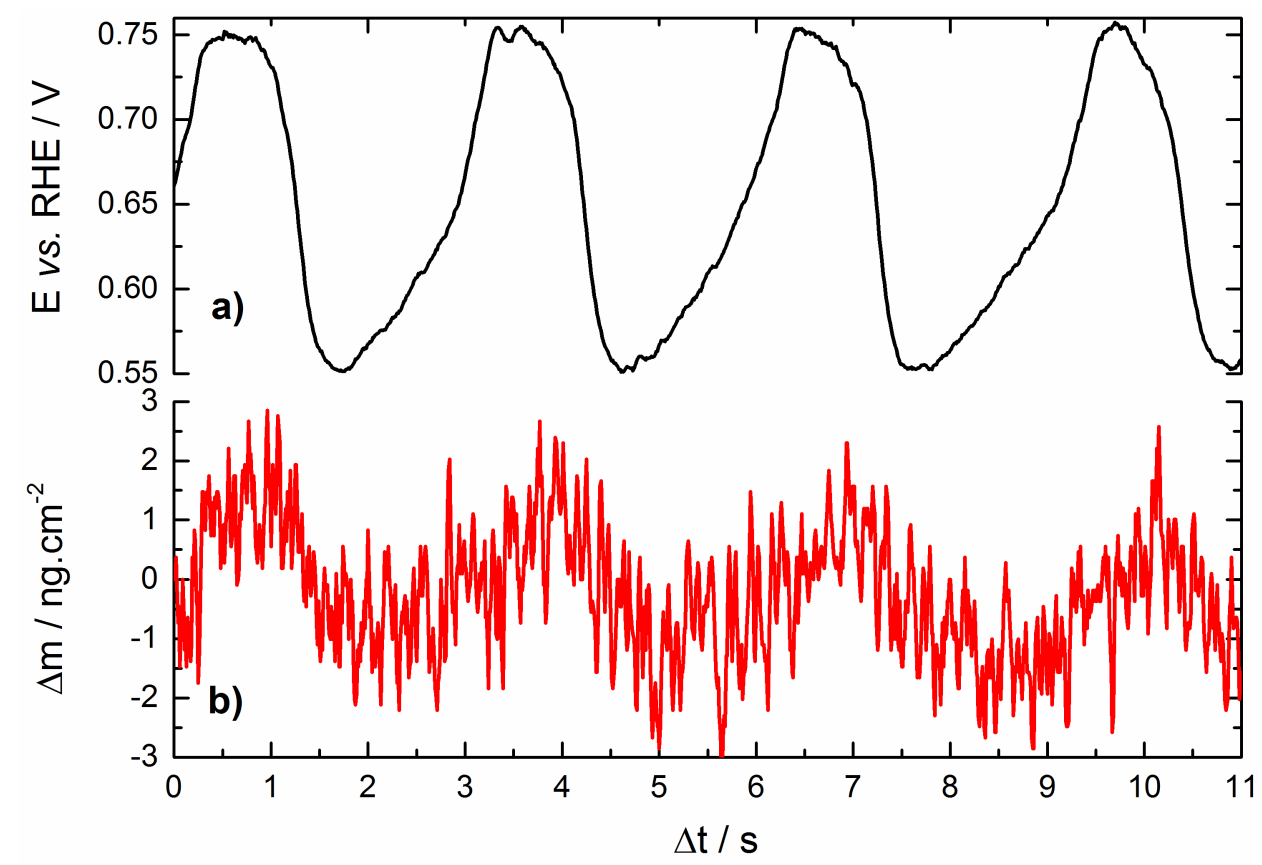

metanol já foi relatada como sendo 1,4 vezes maior em solução de ácido perclórico em relação a uma solução de ácido sulfúrico e, ainda, sendo muito suprimida quando havia a presença de íons $\mathrm{Cl}^{-}$(82).

Comparando a Figura 14 (a) e Figura 16 (a) podemos perceber que a corrente de oxidação é 1,3 vezes maior para a solução de apenas $\mathrm{HClO}_{4}^{-}$. O mesmo efeito é observado em (c), após a adição de metanol em que a corrente máxima de oxidação é 5,8 vezes maior para a solução de $\mathrm{HClO}_{4}^{-}$do que para aquela em que o $\mathrm{HCl}$ foi adicionado. Já em relação à variação de massa, se comparado o mesmo sistema com apenas ácido perclórico, antes e depois da adição de metanol, verifica-se que a maior variação de massa é a mesma, isto é, $59,6 \mathrm{ng} \cdot \mathrm{cm}^{-2}$. Porém, para a solução de com HCl, fazendo a mesma comparação, nota-se que os valores não são os mesmos. Finalmente, comparando os sistemas com e sem $\mathrm{HCl}$, tem-se que a variação de massa é sempre maior para a solução com íons cloreto.

Os resultados da Figura 16 mostram que durante a eletro-oxidação do metanol a variação de massa medida é de 72,6 ng. $\mathrm{cm}^{-1}$. Assim, utilizando a Equação (5.1) é possível calcular $\theta_{O}$ para esse sistema. O valor calculado foi de 3,4. Comparando esse valor com aquele calculado para a solução sem $\mathrm{Cl}^{-}$percebe-se que, contrariamente do que poderia ser esperado baseando-se no argumento de que o cloreto adsorve fortemente impedindo e adiando a oxidação da superfície, comprovado pela medida voltamétrica sem metanol, o valor encontrado é um pouco maior do que para a solução sem cloreto. Como a EQCN mede a variação das espécies que adsorvem/dessorvem da superfície, provavelmente os íons cloretos estão exercendo alguma influência sobre a variação de massa e consequentemente nesse valor calculado. 
Figura 16 - a) Perfil voltamétrico, b) variação de massa durante um ciclo de voltametria contendo apenas eletrólito; c) Perfil voltamétrico e d) variação de massa durante um ciclo de voltametria após a adição de 1,0 mol. $\mathrm{L}^{-1}$ de metanol . Eletrólito: 0,5 mol.L ${ }^{-1}$ de $\mathrm{HClO}_{4}$ e $10^{-6}$ mol.L ${ }^{-1}$ de $\mathrm{HCl}$. Velocidade de varredura: $50 \mathrm{mV} \mathrm{s}^{-1}$.

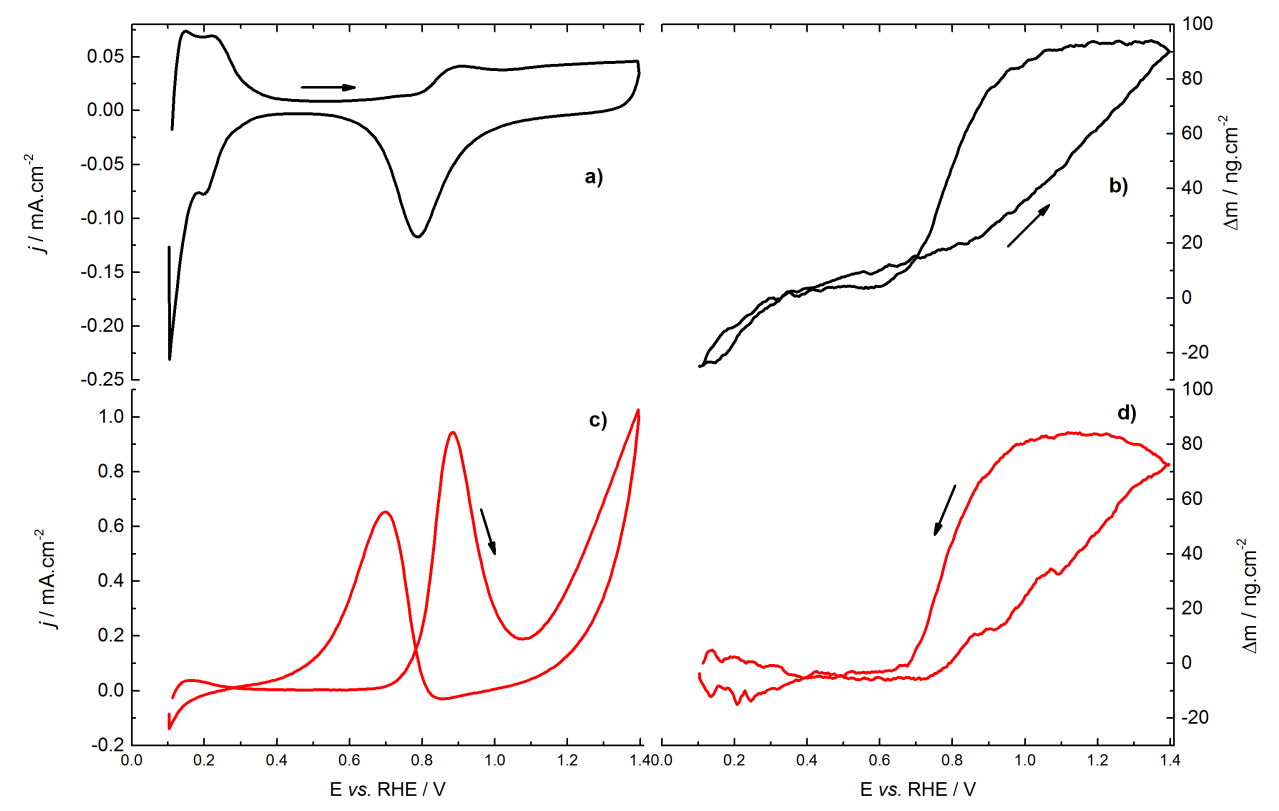

Okamoto e colaboradores (83) mostraram que quando a concentração de íons cloreto era de $10^{-7}$ mol.L ${ }^{-1}$ em uma solução de ácido perclórico, o perfil oscilatório da eletrooxidação de ácido fórmico era praticamente o mesmo quando comparado com o perfil sem $\mathrm{Cl}^{-}$, com exceção de algumas peculiaridades. Ao aumentarem a concentração do íon cloreto para $10^{-5}$ mol. $L^{-1}$ a duração total das oscilações diminuiu e é muito menor em relação aquela com apenas ácido perclórico.

A Figura 17 mostra o perfil oscilatório durante a eletro-oxidação de metanol em $\mathrm{HClO}_{4}$ na presença de $10^{-6}$ mol.L ${ }^{-1}$ de $\mathrm{HCl}$. As oscilações de potencial mostram-se com maior período, sendo este $8,8 \mathrm{~s}$ para a solução com contendo cloreto. O período das oscilações na Figura 15 é de 2,9 s. Essa diferença, provavelmente, deve-se à lenta velocidade de dessorção dos íons cloreto durante o processo oscilatório. 
Figura 17 - Oscilações de potencial (a) e massa (b) para o sistema com 0,5 mol. $\mathrm{L}^{-1}$ de $\mathrm{HClO}_{4}+10^{-6}$ mol.L ${ }^{-1}$ de $\mathrm{HCl}$ e 1,0 mol. $\mathrm{L}^{-1}$ de metanol. $\mathrm{i}=0,49 \mathrm{~mA}$
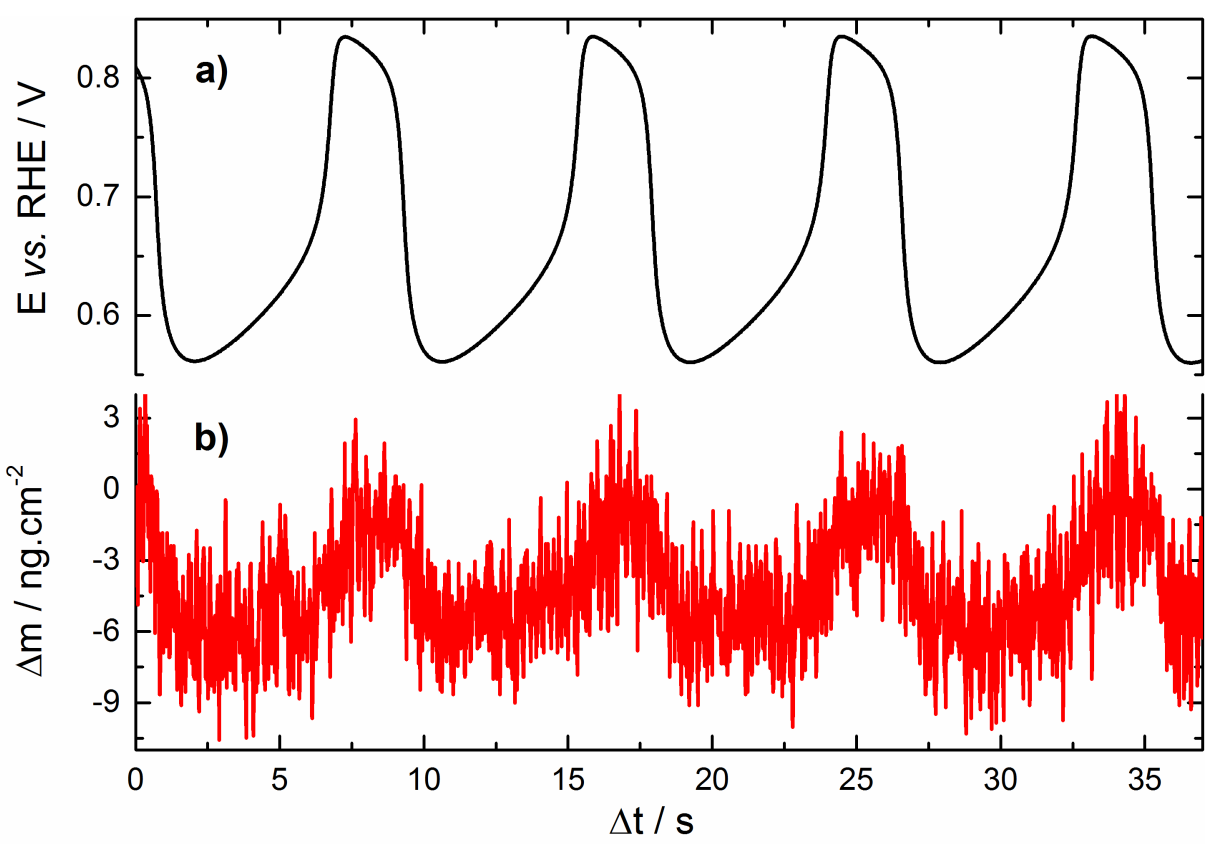

Utilizando os dados da Figura 17 (b) é possível calcular o $\Delta \theta_{C O}$ durante as oscilações. O valor extraído dos experimentos de $\Delta \mathrm{m}$ é $7,6 \mathrm{ng} . \mathrm{cm}^{-2}$. Assim, com a auxílio da equação equação (5.2), o valor calculado é 0,12 .

\subsection{Conclusões do Capítulo}

A eletro-oxidação de metanol foi estudada através de medidas de voltametria cíclica juntamente com medidas nanogravimétricas. Nesse capítulo foram apresentados os resultados dos experimentos com metanol em meio ácido, utilizando como eletrólito de base o ácidos sulfúrico e perclórico e uma solução de ácido perclórico com ácido clorídrico. Durante as oscilações, a variação de massa durante uma oscilação é relativamente pequena, totalizando aproximadamente 4,7, 4,9 $\mathrm{ng} \mathrm{cm}^{-2}$ e 7,6 $\mathrm{ng} \mathrm{cm}^{-2}$ para as respectivas soluções. Com estes valores foi possível calcular qual seria a varição do recobrimento de CO durante uma oscilação, a valores como 0,08 e 0,12 para as soluções sem e com cloreto, respectivamente. Para os experimentos voltamétricos calculou-se qual seria o recobrimento de óxido na superfície de platina durante a oxidação do metanol, sendo este valor de 3,8, 3,1 e 3,4 para o sistema com $\mathrm{H}_{2} \mathrm{SO}_{4}, \mathrm{HClO}_{4}$ e após a adição de $\mathrm{Cl}^{-}$, respectivamente. 


\section{Capítulo 6}

\section{Medidas de Transientes de Potencial de Circuito Aberto}

\subsection{Procedimento Experimental}

Para os experimentos deste Capítulo foram empregados os mesmos eletrólitos utilizados nos Capítulos 4 e 5: KOH (99,99\%, Sigma Aldrich) e LiOH (99,995\%, Alfa Aesar), ambos com concentração de $0,1 \mathrm{~mol} \mathrm{~L}^{-1} ; 0,5 \mathrm{~mol} \mathrm{~L}{ }^{-1}$ de $\mathrm{H}_{2} \mathrm{SO}_{4}$ (97,98\%, J.T.Baker), $0,5 \mathrm{~mol} \mathrm{~L}^{-1}$ de $\mathrm{HClO}_{4}\left(70 \%\right.$, Nuclear) e $0,5 \mathrm{~mol} \mathrm{~L}{ }^{-1}$ de $\mathrm{HClO}_{4}+1,0^{-6} \mathrm{~mol} \mathrm{~L}^{-1}$ de $\mathrm{HCl}$ (37\%, Qhemis). O combustível orgânico estudado foi o $\mathrm{H}_{3} \mathrm{COH}(99,98$, Qhemis) na concentração de $0,1 \mathrm{~mol} \mathrm{~L}^{-1}$ em meio alcalino e $1 \mathrm{~mol} \mathrm{~L}^{-1}$ e $0,5 \mathrm{~mol} \mathrm{~L}^{-1}$ em ácido sulfúrico e ácido perclórico, respectivamente. Todas as soluções foram preparadas com água ultrapura Mili-Q (Millipore 18,2 $\mathrm{m} \Omega . c m$ ).

Após os precedimentos de limpeza e preparação descritos na seção 4.1, o eletrodo de trabalho foi polarizado em alto potencial $\left(\mathrm{E}_{1}\right)$ para a garantir a formação de óxido sobre o catalisador de platina. Em meio alcalino, utilizou-se o potencial de polarização de 1,2 V, já nos experimentos em meio ácido, o potencial utilizado foi de 1,4 V. O tempo de polarização $\left(t_{1}\right)$ também variou conforme o eletrólito, em meio alcalino manteve-se a polarização por $60 \mathrm{~s}$, e nos experimentos em meio ácido esse tempo foi de $300 \mathrm{~s}$. Imediatamente após esse período, o circuito foi aberto para que se estabelecesse o potencial de equilíbrio $\left(\mathrm{E}_{1}\right)$, denominado de potencial de circuito aberto. Nesta etapa foi verificada a variação de massa na superfície do eletrodo Figura 18. Na etapa de polarização é possível acompanhar a variação de massa na superfície do eletrodo, contudo os dados apresentaram muito ruído e descontinuidade. Por essa razão, estes dados não puderam ser utilizados e, assim, não foram inclusos nesse trabalho. 
Figura 18 - Procedimento utilizado para realização das medidas de transiente de potencial de circuito aberto. $E_{1}$ é o potencial de polarização, mantido por $t_{1}$ segundos para garantir a formação de óxido sobre o eletrodo; $t_{2}$ é o tempo no qual acontece o transiente; $\mathrm{E}_{2}$ é o potencial de equilíbrio após o transiente; e $\mathrm{t}_{3}$ é o tempo no qual estabeleceu-se o potencial de equilíbrio.

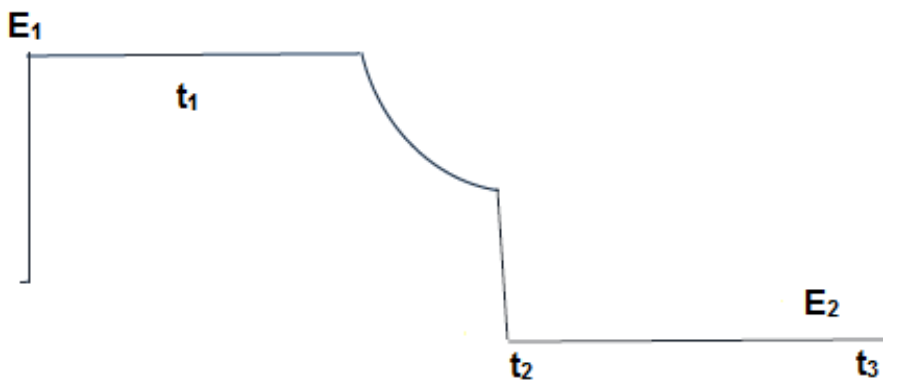

\subsection{Resultados e Discussão}

Batista e Varela (84) discutiram sobre os aspectos que podem influenciar os transientes de circuito aberto em um sitema contendo ácido fórmico e superfície oxidada de platina por meio de experimentos, modelagem e simulação. Podlovchenko e colaboradores (2005) (85), anteriormente, também avaliaram a interação de ácido fórmico com superfícies de platina contendo oxigênio adsorvido na situação de circuito aberto. Já foi mostrado que o oxigênio, sob as condições adotadas para este trabalho, apresenta-se em parte localizado no interior da superfície da platina (21), sendo referido como subsurface oxygen, $\mathrm{O}_{\text {sub }}$. Assim, a disponibilidade de oxigênio na superfície passa a ser mediada pela reação (21):

$$
\mathrm{O}_{\text {sub }}-\mathrm{Pt} \stackrel{k_{1}}{\longrightarrow} \mathrm{Pt}-\mathrm{O}
$$

em que o termo $k_{1}$ é a constante de velocidade para a emergência do $\mathrm{O}_{\text {sub }}$ e $\mathrm{k}_{-1}$ seria para a situação reversa, caracterizando o processo denominado de place exchange. A Figura 19.a mostra o transiente de circuito aberto para os sistemas contendo metanol e $\mathrm{KOH}$ ou LiOH. Quando a superfície do catalisador está altamente recoberta por óxido, foi sugerido que o metanol interage com o eletrodo por meio do mecanismo de Eley-Rideal $(84,86)$ :

$$
\begin{array}{r}
\mathrm{H}_{3} \mathrm{COH}+\mathrm{Pt}-\mathrm{O} \longrightarrow \mathrm{H}_{2} \mathrm{CO}+\mathrm{H}_{2} \mathrm{O}+\mathrm{Pt} \\
\mathrm{Pt}-\mathrm{O}+\mathrm{H}_{2} \mathrm{CO} \longrightarrow \mathrm{Pt}+\mathrm{HCOOH}
\end{array}
$$

A acentuada queda de potencial é acompanhada pela produção de $\mathrm{CO}_{2}$ que, dissolvido, difunde-se ao seio do eletrólito, devido o consumo do óxido na superfície de Pt e, em seguida, também há a formação de $\mathrm{CO}_{\text {ads }}(86)$. Neste ponto, observa-se que a variação de 
Figura 19 - (a) Transiente de circuito aberto e (b) variação de massa durante transiente obtidos para $0,1 \mathrm{~mol} \mathrm{~L}^{-1}$ de metanol em $0,1 \mathrm{~mol} \mathrm{~L}^{-1}$ de $\mathrm{KOH}$ ou $\mathrm{LiOH}$ após a polarização do eletrodo por $60 \mathrm{~s}$ em potencial de $1,2 \mathrm{~V}$

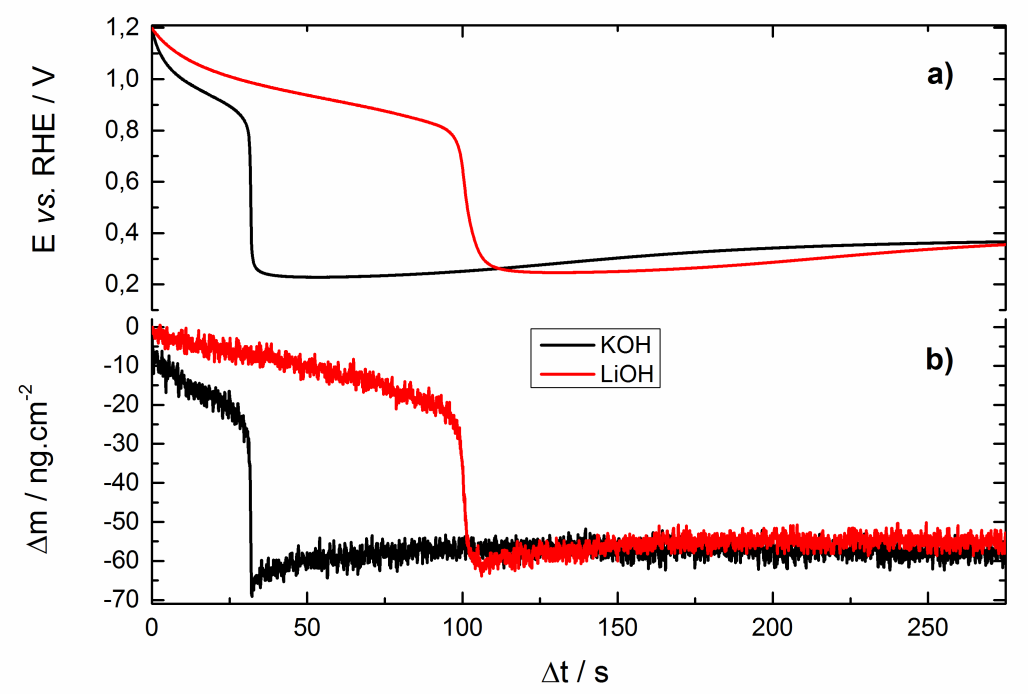

frequência da NECQ aumenta, significando uma diminuição de massa superficial, o que concorda com o aparecimento de $\mathrm{CO}_{2}$ quando parte do óxido já foi inicialmente consumido nos primeiros segundos do experimento. O mecanismo de produção de $\mathrm{CO}$ e $\mathrm{CO}_{2}$ pode ser escrito como (86):

$$
\begin{aligned}
\mathrm{H}_{3} \mathrm{COH}+3 \mathrm{Pt} & \longrightarrow \mathrm{Pt}_{3}-\mathrm{COH}+3 \mathrm{H}^{+}+3 e^{-} \\
\mathrm{Pt}_{3}-\mathrm{COH} & \longrightarrow \mathrm{Pt}-\mathrm{CO}+\mathrm{H}^{+}+e^{-}+2 \mathrm{Pt}
\end{aligned}
$$

Por fim, tem-se a reação entre monóxido de carbono e espécies oxigenadas adsorvidas na superfície produzindo o $\mathrm{CO}_{2}$ dissolvido, por meio do mecanismo de LangmuirHinshelwood:

$$
\mathrm{Pt}-\mathrm{CO}+\mathrm{Pt}-\mathrm{O} \longrightarrow 2 \mathrm{Pt}+\mathrm{CO}_{2} .
$$

Contudo, como não pode haver corrente líquida percorrendo o circuito, as equações 6.3 e 6.4 são somadas com a reação de redução de óxido (84):

$$
\mathrm{Pt}-\mathrm{O}+2 \mathrm{H}^{+}+2 e^{-} \longrightarrow \mathrm{Pt}+\mathrm{H}_{2} \mathrm{O}
$$

Assim, a reação global é escrita da forma (84):

$$
\mathrm{H}_{3} \mathrm{COH}+3 \mathrm{Pt}-\mathrm{O}+3 \mathrm{Pt} \longrightarrow \mathrm{CO}_{2}+2 \mathrm{H}_{2} \mathrm{O}+6 \mathrm{Pt} .
$$

Como pode ser visto, 3 sítios livres de Pt produzem 6 sítios do mesmo, sendo este processo denominado como um processo autocatalítico. À autocatálise de sítios livres de platina 
atribui-se a causa pelo processo acelerado de decréscimo de potencial observado após aproximadamente $30 \mathrm{~s}$ em que o circuito foi aberto para a solução formada por $0,1 \mathrm{~mol} \mathrm{~L}^{-1}$ de $\mathrm{KOH}$ e aproximadamente $100 \mathrm{~s}$ para a solução contendo $0,1 \mathrm{~mol} \mathrm{~L}^{-1} \mathrm{LiOH}$ (Figura 19).

Comparando os transientes de circuito aberto para a solução de $\mathrm{KOH}$ e a de LiOH, pode-se notar que o tempo gasto para o consumo de óxido é maior para o LiOH. Mais uma vez, de alguma forma os clusters formados com os íons $\mathrm{Li}^{+}$podem estar impedindo a chegada de metanol à superfície para reagir com a camada de óxido ou a ligação $\mathrm{Pt}-\mathrm{O}$ está sendo muito mais favorecida na solução de LiOH.

A variação de massa que ocorre até o eletrodo estar totalmente livre de óxido, ou seja, até o potencial mínimo do transiente, corrobora com a questão levantada no parágrafo anterior. Para a solução contendo $\mathrm{KOH}$, a variação de massa observada foi de $-69,0 \mathrm{ng} \mathrm{cm}^{-2}$, por outro lado, na solução contendo LiOH foi obtido uma variação de massa de $-62,3 \mathrm{ng} \mathrm{cm}^{-2}$. Isso revela que um maior recobrimento de óxido ocorre na situação em que o eletrólito de base é o $\mathrm{KOH}$, como foi visto nas medidas de voltametria cíclica. A razão entre as variações de massa mostra que esse recobrimento é 1,1 vez maior na primeira situação. Pode-se chegar à mesma conclusão através das Figuras 6 e 7. No momento em que todo óxido é consumido, o eletrodo está livre para que ocorra a formação de CO (86). Assim, a Figura 19 mostra que para os dois casos estudados a massa final e o potencial de equilíbrio são consideravelmente os mesmos. Partindo dessa observação, é possível estimar a quantidade relativa de $\mathrm{CO}_{\text {ads }}$ para os sistemas em questão. Foi encontrado que a variação de massa após o todo o consumo da camada de óxido até o potencial de equilíbrio foi de $10,9 \mathrm{ng} \mathrm{cm}^{-2}$ e $4,2 \mathrm{ng} \mathrm{cm}^{-2}$ para as soluções de $\mathrm{KOH}$ e $\mathrm{LiOH}$, respectivamente. Essa menor variação de massa que é medida quando se tem $\mathrm{Li}^{+}$ no meio reacional relaciona-se com o que já foi discutido anteriormente sobre o influência dos clusters na superfície do eletrodo. Estando o eletrodo mais bloqueado, menos metanol reage com a superfície de Pt e menos CO é formado. De modo geral, o experimento de circuito aberto concorda com os aspectos observados na voltametria cíclica, no que diz respeito aos maiores picos de oxidação obtidos para o sistema composto por $\mathrm{KOH}$.

Outro experimento de circuito aberto foi realizado com o metanol em meio ácido, usando solução aquosa de $\mathrm{H}_{2} \mathrm{SO}_{4}$ como eletrólito de base. Neste caso, como a formação de óxido é menos favorecida em relação ao meio alcalino, foi necessário utilizar um potencial mais elevado durante a polarização e por período de tempo maior. A Figura 20 ilustra os resultados obtidos.

Os resultados mostram que durante o período de diminuição do potencial de 1,4 V até $0,12 \mathrm{~V}$ a massa superficial sofre uma diminuição de $139,1 \mathrm{ng} \mathrm{\textrm {cm } ^ { - 2 }}$, associada à redução do óxido formado no durante o período de polarização. Como já mencionado, esse processo ocorre através de dois mecanismos, inicialmente pelo mecanismo de Eley-Rideal e posteriormente pelo mecanismo de Langmuir-Hinshelwood. Para este, tem-se a variação de massa de $94,4 \mathrm{ng} \mathrm{cm}^{-2}$, e àquele, 44,7 $\mathrm{ng} \mathrm{cm}^{-2}$. Quando a superfície está totalmente livre 
Figura 20 - a) Transiente de potencial de circuito aberto e (b) variação de massa durante transiente obtidos para $1 \mathrm{~mol} \mathrm{~L}^{-1}$ de metanol em $0,5 \mathrm{~mol} \mathrm{~L}^{-1}$ de $\mathrm{H}_{2} \mathrm{SO}_{4}$ após a polarização do eletrodo por $300 \mathrm{~s}$ em potencial de $1,4 \mathrm{~V}$

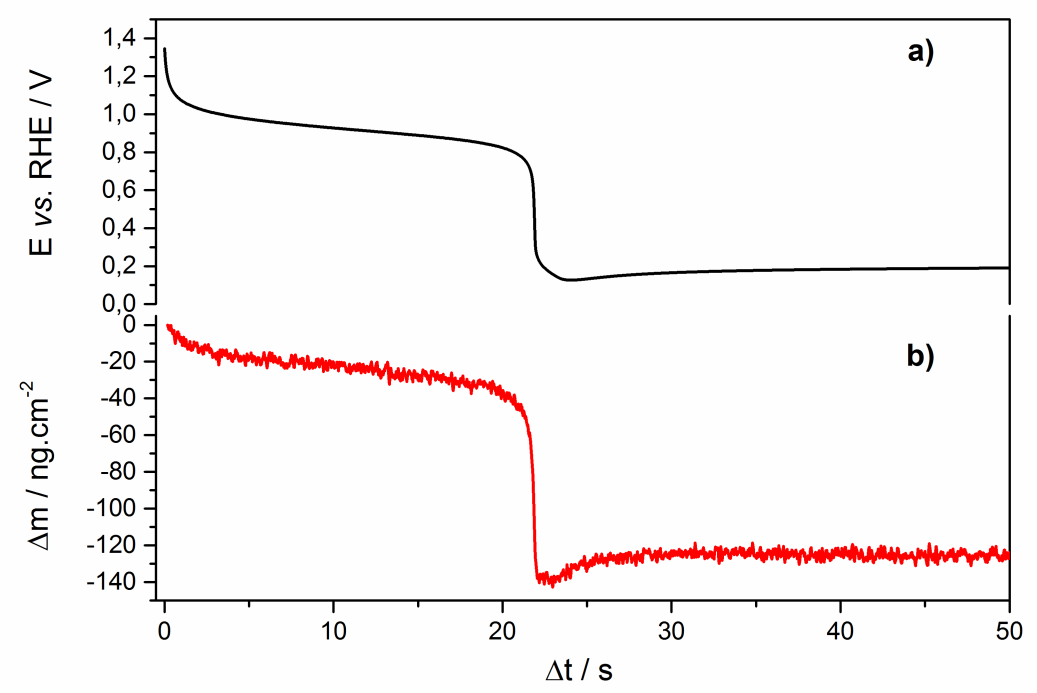

de óxido, a formação de CO é iniciada resultando em um aumento da massa superficial de $14.9 \mathrm{ng} \mathrm{cm}^{-2}$ em um primeiro momento e após os $400 \mathrm{~s}$ que esperou-se para estabilização do potencial de equilíbrio, essa massa sofre uma pequena redução de aproximadamente $6,1 \mathrm{ng} \mathrm{cm}^{-2}$, como confirma a Figura 20.b.

Posteriormente, as soluções contendo ácido perclórico foram submetidas ao experimento de circuito aberto. Os resultados obtidos encontram-se na Figura 21.

Como já mencionado, 3 sítios livres de Pt produzem 6 sítios do mesmo, sendo este processo denominado como um processo autocatalítico. Assim, à autocatálise de sítios livres de platina atribui-se a causa pelo processo acelerado de decréscimo de potencial observado após aproximadamente 9,1 s para a solução isenta de íons cloreto e 31,6 s para a solução com presença de íons cloreto, em que o circuito foi aberto, de acordo com a Figura 21 (a) e (c). Comparando os transientes de circuito aberto entre as duas soluções, pode-se notar que o tempo gasto para o consumo de óxido é maior para o aquela que contém $\mathrm{Cl}^{-}$. A influência deste ânion, apesar de aumentar o tempo do transiente, não altera a sua forma.

Para a solução constituída apenas $\mathrm{HClO}_{4}$, a variação de massa observada foi de $-110,1 \mathrm{ng} \mathrm{cm}^{-2}$, por outro lado, na solução contendo $\mathrm{Cl}^{-}$foi obtido uma variação de massa

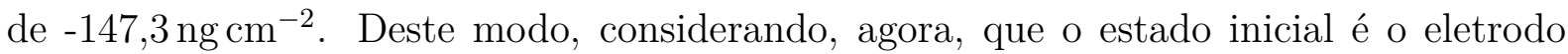
todo recoberto por óxido e que o processo de consumo desse óxido faz com que a variação de massa seja conforme descrito no início do parágrafo; o estado final corresponde ao eletrodo recoberto por aproximadamente $75 \%$ de sua área por CO. Assim, foi utilizada a equação Equação (5.1) para estimar o valor de $\theta_{O}$. O valor da variação de massa final, ou seja, aquele correspondente a potenciais mais baixos, quando tem-se 0,75 de $\theta_{C O}$ é 
Figura 21 - (a) Transiente de circuito aberto e (b) variação de massa durante transiente obtidos para 0,5 mol.L $\mathrm{L}^{-1}$ de $\mathrm{HClO}_{4}$ e 1,0 mol.L ${ }^{-1}$ de metanol; (c) transiente de circuito aberto e $(\mathrm{d})$ variação de massa durante o transiente para o sistema composto por 0,5 mol. $\mathrm{L}^{-1}$ de $\mathrm{HClO}_{4}+10^{-6}$ mol.L $\mathrm{L}^{-1}$ de $\mathrm{HCl}$ e $1,0 \mathrm{~mol} . \mathrm{L}^{-1}$ de metanol, após a polarização do eletrodo por $300 \mathrm{~s}$ em potencial de $1,4 \mathrm{~V}$.

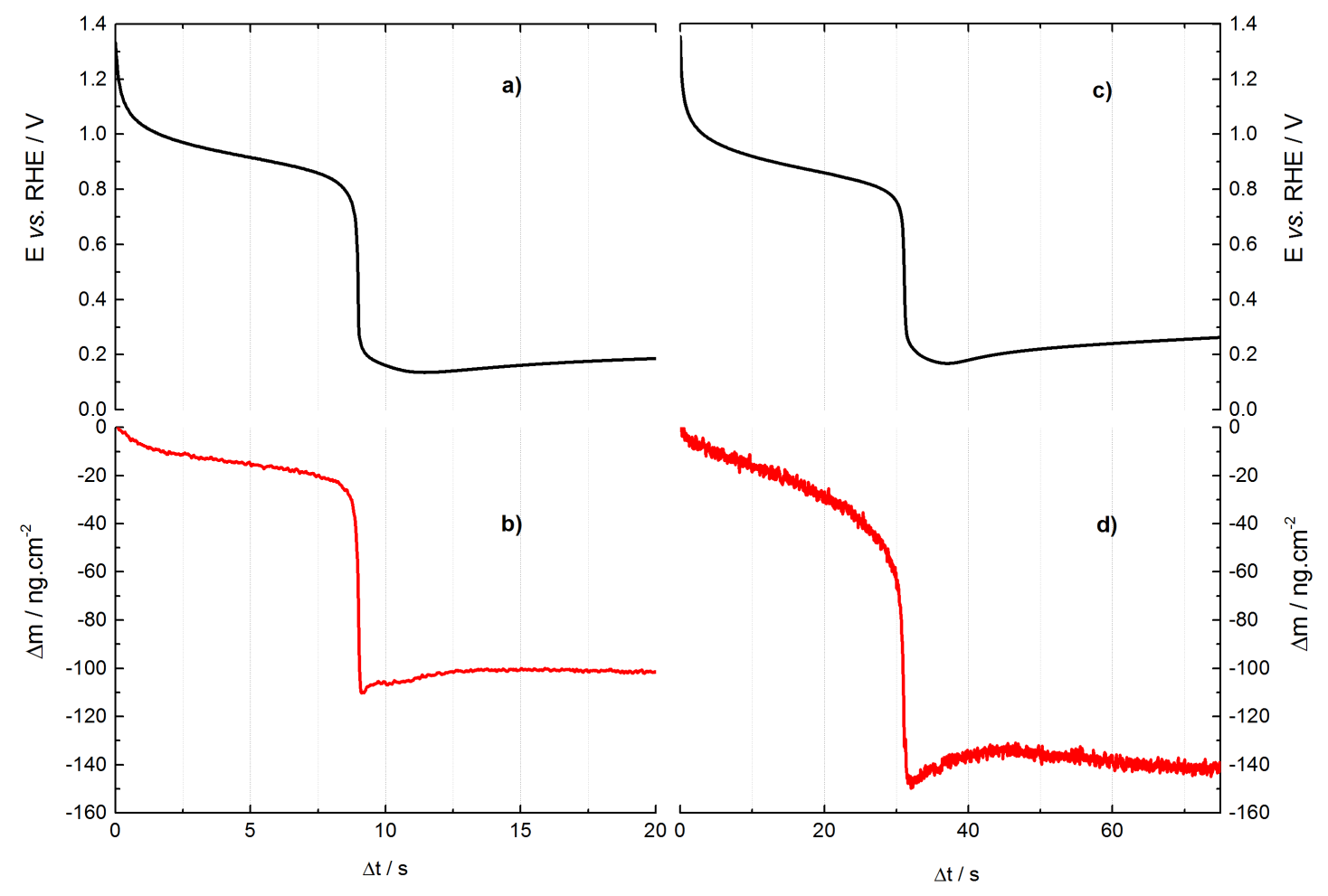

-100,5 ng.cm ${ }^{-2}$ para a solução sem cloreto e de $-133,3$ ng.cm ${ }^{-2}$ para a solução com cloreto, assim o valor assumido por $\theta_{O}$ para a solução sem cloreto é:

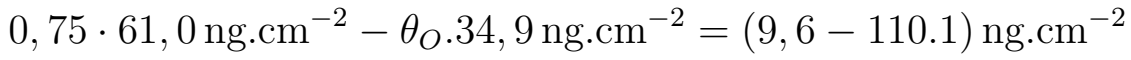

$$
\begin{aligned}
& \theta_{O}=4,2 \text {. }
\end{aligned}
$$

E para a solução contendo cloreto:

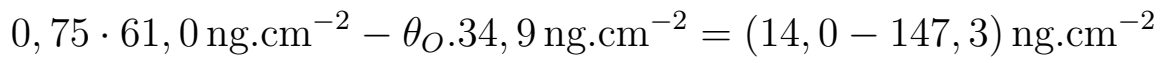

$$
\begin{aligned}
& \theta_{O}=5,1 .
\end{aligned}
$$

Como pode ser observado, o valor de $\theta_{O}$ para a solução com $\mathrm{Cl}^{-}$é 0,8 vezes maior do que a solução sem estes íons. Contudo, segundo Sitta e Varela (21) o tempo para consumo do óxido é maior conforme aumenta-se a energia de quimissorção do ânion em solução, implicando, assim, na quantidade de sítios livres de Pt que estão disponíveis durante o transiente de potencial de circuito aberto. Outro ponto a mencionar é que o processo de quimissorção dos ânions compete com o metanol e seus resíduos durante todo o transiente e não apenas nas regiões de baixo potencial. Esse efeito, obviamente, interfere na variação de massa influindo para valor superior do que realmente seria se não houvesse 
o processo de quimissorção. Então, pode-se perceber que, uma vez que os ânions cloreto adiam a oxidação da superfície, para que o suposto valor de $\theta_{O}$ seja maior na solução contendo esse íon, este mesmo deve estar contribuindo para que se perceba, através dos cálculos, um maior recobrimento de óxido na Figura 21 (c).

\subsection{Conclusão do Capítulo}

Os experimentos transientes de potencial de circuito aberto é método muito simples de ser executado e de grande valor para o estudo do processo de interação do metanol com a superfície oxidada do catalisador. Os resultados obtidos nesse trabalho mostraram que os experimentos conduzidos em meio alcalino apresentam, em geral, maior tempo de transiente. Isso é muito mais evidente quando tem-se uma solução aquosa de LiOH, pois, como observado, o maior tempo de transiente foi especificamente para este caso. Em relação aos experimentos em meio ácido, aquele realizado com $\mathrm{HClO}_{4}$ aquoso contendo íons cloreto foi o que apresentou o maior tempo de transiente e, dentre todos os experimentos (incluindo aqueles realizados em meio alcalino), também apresentou a maior variação de massa durante o transiente.

Esses resultados são decorrentes da influência exercida pelos ânions ou cátions presentes em cada sistema. Os cátions dos metais alcalinos, $\mathrm{Li}^{+} \mathrm{e} \mathrm{K}^{+}$, bloqueiam a superfície tanto para a formação de óxido quanto para que o combustível orgânico possa interagir com a superfície oxidada após a abertura do circuito, como o lítio bloqueia mais em relação ao potássio, o tempo de transiente é maior para o primeiro caso. Quanto a variação de massa observada, a solução com íons $\mathrm{K}^{+}$mostrou uma maior variação, provavelmente devido a maior formação de óxido de platina em relação à solução com $\mathrm{Li}^{+}$.

Em meio ácido, a menor variação de massa foi para o experimento realizado em solução aquosa de $\mathrm{HClO}_{4}$, bem como também o menor tempo de transiente, seguido do experimento conduzido em solução aquosa de $\mathrm{H}_{2} \mathrm{SO}_{4}$ e, como já mencionado, a maior variação de massa e maior tempo de transiente foram observados para o experimento contendo $\mathrm{HClO}_{4}$ e íons cloreto. É possível perceber aqui a correlação entre a energia de adsorção dos ânions presentes em solução com o tempo do transiente e a perda de massa durante o transiente. É possível concluir que os ânions presentes nas soluções estão contribuindo de algum modo para a diferença observada nas variações de massas, pois caso não houvesse essa influência dos ânion, a maior massa deveria ser observada na solução de metanol e $\mathrm{HClO}_{4}$ aquoso, visto que este adsorve mais fracamente na superfície do eletrodo e proporcionaria, deste modo, uma maior formação de óxido de platina durante a polarização do eletrodo, bem como a maior variação de massa. 


\section{Capítulo 7}

\section{Considerações Finais}

Este trabalho apresentou um acompanhamento da variação de massa superficial durante a eletro-oxidação de metanol sobre platina em diferentes meios utilizando a técnica de nanogravimetria. Com os resultados obtidos, procurou-se demonstrar qual seria a massa molar presente na superfície do eletrodo durante o seu processo de oxidação na presença e na ausência do combustível orgânico. Foi constatado, em meio alcalino, que a massa molar na superfície foi maior para o caso em que o eletrólito de base utilizado foi o $\mathrm{LiOH}$, para os experimentos em meio alcalino. Não obstante, após a adição do metanol, durante o processo de oxidação do combustível, encontrou-se uma maior variação de massa para o experimento realizado em $\mathrm{KOH}$ aquoso. Ademais, nos experimentos de transiente de potencial de circuito aberto, a perda de massa observada é maior para o caso em que se tem $\mathrm{K}^{+}$na solução. Para os experimentos em meio ácido, a influência dos ânions torna-se um quesito fundamental, de modo que os resultados estavam relacionados com a energia de adsorção destes ânions.

O processo de eletro-oxidação oscilatória do metanol, que só pode ser observado em meio ácido, apresentou aspectos de massa diferentes para cada eletrólito de base utilizado. Com os dados de massa obtidos com a nanobalança eletroquímica de cristal de quartzo, foi possível estimar um valor para a variação de recobrimento de $\mathrm{CO}$ durante as oscilações. $\mathrm{O}$ valor obtido para os experimentos conduzidos em $\mathrm{HClO}_{4}$ e $\mathrm{H}_{2} \mathrm{SO}_{4}$ aquosos foi de 0,08 de uma monocamada, já para o experimento em que foi feita a adição de íons cloreto esse valor foi um pouco superior, correspondendo a 0,12 de uma monocamada. O que se observa também durante as oscilações é que para este último caso a variação de massa é a maior em relação aos outros dois casos.

No capítulo final, a abordagem envolvendo os transientes de potencial de circuito aberto revela em um primeiro momento a influência dos clusters sobre o processo de 
consumo da camada de óxido de platina. A presença dos íons $\mathrm{Li}^{+}$atrasa, em relação ao experimento realizado com hidróxido de potássio aquoso, a etapa em que ocorre a autocatálise da produção de sítios livre de platina, marcada pela rápida diminuição de potencial. Foi verificado também que uma maior variação de massa é obtida durante o transiente para o experimento em hidróxido de potássio. Em um outro momento, observou-se que para os experimentos em meio ácido o transiente mais longo foi para a solução contente íons cloreto, bem como a maior variação de massa. Consequentemente, a o maior $\theta_{O}$ também foi para este caso. Como o cloreto adsorve quimicamente à superfície de platina (60) é possível que nos valores encontrados para variação de massa estejam inseridos a contribuição do íon cloreto. Fica difícil, utilizando apenas a técnica de nanogravimetria, distinguir a contribuição de cada espécie para a variação de massa observada. Possivelmente associada a outra técnica, como por exemplo a espectroscopia de infravermelho, poderemos elucidar esta questão. 


\section{REFERÊNCIAS}

1 NAGAO, R. et al. The dual pathway in action: decoupling parallel routes for $\mathrm{CO}_{2}$ production during the oscillatory electro-oxidation of methanol. Physical Chemistry Chemical Physics, v. 14, p. 8294-8298, 2012.

2 PRIGOGINE, I. O fim das certezas: tempo, caos e as leis da natureza: tempo, caos e as leis da natureza. 2. ed. São Paulo: Unesp, 2011. 205 p.

3 NICOLIS, G.; PRIGOGINE, I. Self-Organization in nonequilibrium systems: From dissipative structures to order through fluctuations. New York: Wiley, 1977.

4 GLANSDORFF, P.; PRIGOGINE, I. Thermodynamic theory of structure, stability and fluctuations. London: Wiley-Interscience, 1971.

5 BUZSAKI, G.; DRAGUHN, A. A neuronal oscillations in cortical networks. Science, v. 304, p. 1926-1929, 2004.

6 GLASS, L. Synchronization and rhythmic processes in physiology. Nature, v. 410, n. 6825 , p. 277-284, 2001.

7 WINFREE, A. T. The geometry of biological time. New York: Springer-Verlag, 2001.

8 WINFREE, A. T. On emerging coherence. Science, American Association for the Advancement of Science, v. 298, n. 5602, p. 2336-2337, 2002.

9 BARD, A. J.; FAULKNER, L. R. Electrochemical methods: Fundamentals and applications. 2. ed. New York: Wiley, 2001.

10 KOPER, M. T. M.; HACHKAR, M.; BEDEN, B. Investigation of the oscillatory electro-oxidation of formaldehyde on $\mathrm{Pt}$ and $\mathrm{Rh}$ electrodes by cyclic voltammetry, impedance spectroscopy and the electrochemical quartz crystal microbalance. Journal of the Chemical Society, v. 92, p. 3975-3982, 1996.

11 CHEN, S. li; WU, B. liang; CHA, C. sin. An EQCM investigation of oxidation of formic acid at gold electrode in sulfuric acid solution. Journal of Electroanalytical Chemistry, v. 431, n. 2, p. $243-247,1997$. 
12 PARSONS, R.; VANDERNOOT, T. The oxidation of small organic molecules. Journal of Electroanalytical Chemistry and Interfacial Electrochemistry, v. 257, n. 1 , p. $9-45,1988$.

13 SHRIVASTAVA, N. K.; HARRIS, T. A. L. Direct methanol fuel cells. In: ABRAHAM, M. A. (Ed.). Encyclopedia of Sustainable Technologies. Oxford: Elsevier, 2017. p. 343-357.

14 SAMIMI, F.; RAHIMPOUR, M. R. Chapter 14 - direct methanol fuel cell. In: BASILE, A.; DALENA, F. (Ed.). Methanol. [S.l.]: Elsevier, 2018. p. 381-397.

15 LIU, H. et al. A review of anode catalysis in the direct methanol fuel cell. Journal of Power Sources, v. 155, n. 2, p. 95-110, 2006.

16 GUO, J. W. et al. Preparation and characterization of a ptru/c nanocatalyst for direct methanol fuel cells. Electrochimica Acta, v. 51, n. 4, p. 754-763, 2005.

17 MAJIDI, P. et al. Determination of the efficiency of methanol oxidation in a direct methanol fuel cell. Electrochimica Acta, v. 199, p. 210-217, 2016.

18 WATANABE, M.; MOTOO, S. Electrocatalysis by ad-atoms: Part ii. enhancement of the oxidation of methanol on platinum by ruthenium ad-atoms. Journal of Electroanalytical Chemistry and Interfacial Electrochemistry, v. 60, n. 3, p. 267-273, 1975.

19 FRELINK, T.; VISSCHER, W.; VEEN, J. A. R. van. On the role of ru and sn as promotors of methanol electro-oxidation over pt. Proceedings of the IUVSTA Workshop on Surface Science and Electrochemistry, v. 335, p. 353-360, 1995.

20 PAGANIN, V. A. et al. Methanol crossover effect on the cathode potential of a direct pem fuel cell. Journal of Applied Electrochemistry, v. 35, n. 12, p. 1239-1243, 2005.

21 SITTA, E.; VARELA, H. On the open-circuit interaction between methanol and oxidized platinum electrodes. Journal of Solid State Electrochemistry, v. 12, n. 5, p. 559-567, 2008.

22 BRUCKENSTEIN, S.; SHAY, M. Experimental aspects of use of the quartz crystal microbalance in solution. Electrochimica Acta, v. 30, n. 10, p. 1295 - 1300, 1985.

23 MELROY, O. et al. Direct determination of the mass of an underpotentially deposited monolayer of lead on gold. Langmuir, v. 2, n. 6, p. 697-700, 1986.

24 SEO, M.; YOSHIDA, K.; NODA, K. A quartz crystal microbalance study of the corrosion of iron thin films in neutral aqueous solutions. Materials Science and Engineering: A, v. 198, n. 1, p. $197-203,1995$.

25 YURT, A.; AYKiN Özlem. Diphenolic Schiff bases as corrosion inhibitors for aluminium in $0.1 \mathrm{M} \mathrm{HCl}$ : Potentiodynamic polarisation and EQCM investigations. Corrosion Science, v. 53, n. 11, p. 3725 - 3732, 2011.

26 LEI, H. W.; UCHIDA, H.; WATANABE, M. Electrochemical quartz crystal microbalance study of halide adsorption and concomitant change of surface excess of water on highly ordered $\mathrm{Au}(111)$. Langmuir, v. 13, n. 13, p. 3523-3528, 1997. 
27 SANTOS, M. et al. Study of anion adsorption on polycrystalline pt by electrochemical quartz crystal microbalance. Electrochemistry Communications, v. 2, n. 10, p. 692 -696, 2000.

28 ZOLFAGHARI, A.; CONWAY, B. E.; JERKIEWICZ, G. Elucidation of the effects of competitive adsorption of $\mathrm{Cl}^{-}$and $\mathrm{Br}^{-}$ions on the initial stages of $\mathrm{Pt}$ surface oxidation by means of electrochemical nanogravimetry. Electrochimica Acta, v. 47, n. 8, p. 1173 $-1187,2002$.

29 BRUCKENSTEIN, S.; SHAY, M. An in situ weighing study of the mechanism for the formation of the adsorbed oxygen monolayer at a gold electrode. Journal of Electroanalytical Chemistry and Interfacial Electrochemistry, v. 188, n. 1, p. 131 - 136, 1985.

30 BIRSS, V.; CHANG, M.; SEGAL, J. Platinum oxide film formation-reduction: an in-situ mass measurement study. Journal of Electroanalytical Chemistry, v. 355, n. 1 , p. $181-191,1993$.

31 TIAN, M.; CONWAY, B. E. Electrocatalysis in oscillatory kinetics of anodic oxidation of formic acid: At Pt; nanogravimetry and voltammetry studies on the role of reactive surface oxide. Journal of Electroanalytical Chemistry, v. 616, n. 1-2, p. 45 $-56,2008$.

32 NOGUEIRA, J. A. et al. Autonomous voltage oscillations in a direct methanol fuel cell. Electrochimica Acta, v. 212, p. 545-552, 2016.

33 PRIGOGINE, I. Introduction to thermodynamics of irreversible processes. 3. ed. New York: John Wiley \& Sons, 1965.

34 ZHABOTINSKY, A. M. Periodical oxidation of malonic acid in solution (a study of the belousov reaction kinetics). Biofizika, v. 9, p. 306-311, 1964.

35 STROGATZ, S. H. Nonlinear dynamics and chaos: With applications to physics, biology, chemistry and engeering. Cambridge: Addison-Wesley, 1994.

36 ORLIK, M. Self-organization in electrochemical system I. Berlin: Springer-Verlag, 2012.

37 KRISCHER, K.; VARELA, H. Oscillations and other dynamic instabilities. In: VIELSTICH, W. et al. (Ed.). Handbook of Fuel Cells: Fundamentals, technology and applications. [S.1.]: John Wiley \& Sons, Ltd, 2010. v. 92, p. 679-701.

38 KOPER, M. T. M. The theory of electrochemical instabilities. Electrochimica Acta, v. 37, n. 10, p. $1771-1778,1992$.

39 JERKIEWICZ, G. et al. Surface-oxide growth at platinum electrodes in aqueous $\mathrm{H}_{2} \mathrm{SO}_{4}$ : Reexamination of its mechanism through combined cyclic-voltammetry, electrochemical quartz-crystal nanobalance, and auger electron spectroscopy measurements. Electrochimica Acta, v. 49, n. 9-10, p. 1451 - 1459, 2004.

40 LAMY, C. Electrocatalytic oxidation of organic compounds on noble metals in aqueous solution. Electrochimica Acta, v. 29, n. 11, p. 1581-1588, 1984. 
41 BEDEN, B. et al. Infrared spectroscopic study of the methanol adsorbates at a platinum electrode: Part iii. structural effects and behaviour of a polycrystalline surface. Journal of Electroanalytical Chemistry and Interfacial Electrochemistry, v. 238, n. 1, p. 323-331, 1987.

42 SANTOS, E. et al. Comparative study of co absorbates for different structures of platinum surfaces. Journal of Electroanalytical Chemistry and Interfacial Electrochemistry, v. 227, n. 1, p. 199-211, 1987.

43 GOODENOUGH, J. B. et al. Xps investigation of platinized carbon electrodes for the direct methanol air fuel cell. Electrochimica Acta, v. 32, n. 8, p. 1233-1238, 1987.

44 SNELL, K. D.; KEENAN, A. G. Effect of anions and ph on the ethanol electrooxidation at a platinum electrode. Electrochimica Acta, v. 27, n. 12, p. 1683-1696, 1982.

45 LEIVA, E. P. M.; GIORDANO, M. C. Multiple current components for methanol electrosorption and electro-oxidation at platinum in acidic solutions. Journal of Electroanalytical Chemistry and Interfacial Electrochemistry, v. 158, n. 1, p. 115-130, 1983.

46 SRINIVASAN, S. Fuel cells for electric utility and transportation applications. Proceedings of the Fifth Australian Electrochemistry Conference, v. 118, p. 51-69, 1981.

47 ENYO, M. Anodic formaldehyde oxidation on Pt, Pd, Au and Pd-Au alloy electrodes in $\mathrm{NaOH}$ and $\mathrm{Na} 2 \mathrm{CO} 3$ solutions. Journal of Applied Electrochemistry, v. 15, n. 6, p. 907-911, 1985.

48 BELTOWSKA-BRZEZINSKA, M.; HEITBAUM, J. On the anodic oxidation of formaldehyde on pt, au and pt/au-alloy electrodes in alkaline solution. Journal of Electroanalytical Chemistry and Interfacial Electrochemistry, v. 183, n. 1, p. 167-181, 1985.

49 IWASITA, T.; VIELSTICH, W. On-line mass spectroscopy of volatile products during methanol oxidation at platinum in acid solutions. Journal of Electroanalytical Chemistry and Interfacial Electrochemistry, v. 201, n. 2, p. 403-408, 1986.

50 OTA, K.-I.; NAKAGAWA, Y.; TAKAHASHI, M. Reaction products of anodic oxidation of methanol in sulfuric acid solution. Journal of Electroanalytical Chemistry and Interfacial Electrochemistry, v. 179, n. 1, p. 179-186, 1984.

51 STRASSER, P.; EISWIRTH, M.; KOPER, M. T. Mechanistic classification of electrochemical oscillators - an operational experimental strategy. Journal of Electroanalytical Chemistry, v. 478, n. 1-2, p. 50 - 66, 1999.

52 GOJUKI, T. et al. Hidden negative differential resistance in the oxidation of formic acid on platinum. Electrochimica Acta, v. 129, p. 142 - 151, 2014.

53 NEUROCK, M.; JANIK, M.; WIECKOWSKI, A. A first principles comparison of the mechanism and site requirements for the electrocatalytic oxidation of methanol and formic acid over Pt. Faraday Discussion, v. 140, p. 363-378, 2009. 
54 PERINI, N. et al. Electrocatalytic activity under oscillatory regime: The electro-oxidation of formic acid on ordered Pt3Sn intermetallic phase. Catalysis Communications, v. 30, p. $23-26,2013$.

55 CAPON, A.; PARSON, R. The oxidation of formic acid at noble metal electrodes. Journal of Electroanalytical Chemistry and Interfacial Electrochemistry, v. 44, n. 1, p. $1-7,1973$.

56 CAPON, A.; PARSONS, R. The oxidation of formic acid on noble metal electrodes. Journal of Electroanalytical Chemistry and Interfacial Electrochemistry, v. 44, n. 2 , p. $239-254,1973$.

57 CAPON, A.; PARSONS, R. The oxidation of formic acid at noble metal electrodes part iii. intermediates and mechanism on platinum electrodes. Journal of Electroanalytical Chemistry and Interfacial Electrochemistry, v. 45, n. 2, p. 205 - 231, 1973.

58 CAPON, A.; PARSONS, R. The oxidation of formic acid at noble metal electrodes part 4. platinum + palladium alloys. Journal of Electroanalytical Chemistry and Interfacial Electrochemistry, v. 65, n. 1, p. 285 - 305, 1975.

59 BRIMAUD, S. et al. Formic acid electrooxidation on noble-metal electrodes: Role and mechanistic implications of $\mathrm{pH}$, surface structure, and anion adsorption. ChemElectroChem, v. 1, n. 6, p. 1075-1083, 2014.

60 BAGOTZKY, V.; VASSILIEV, Y.; KHAZOVA, O. Generalized scheme of chemisorption, electrooxidation and electroreduction of simple organic compounds on platinum group metals. Journal of Electroanalytical Chemistry and Interfacial Electrochemistry, v. 81, n. 2, p. 229 - 238, 1977.

61 MARTINS, A. L. et al. Oscillatory instabilities during the electrocatalytic oxidation of methanol on platinum. Journal of the Brazilian Chemical Society, scielo, v. 19, p. $679-687,2008$.

62 BOSCHETO, E. et al. A surface-enhanced infrared absorption spectroscopic (SEIRAS) study of the oscillatory electro-oxidation of methanol on platinum. Journal of Electroanalytical Chemistry, v. 642, n. 1, p. $17-21,2010$.

63 STRMCNIK, D. et al. The role of non-covalent interactions in electrocatalytic fuel-cell reactions on platinum. Nature Chemistry, v. 1, p. $466-472,2009$.

64 MOTOO, S. M.; SHIBATA, M. Electrocatalysis by ad-atoms: Part ix. a fast parallel path for formaldehyde oxidation on a platinum electrode by oxygen adsorbing ad-atoms. Journal of Electroanalytical Chemistry and Interfacial Electrochemistry, v. 139, n. 1, p. 119-130, 1982.

65 BUTTRY, D. A.; WARD, M. D. Measurement of interfacial processes at electrode surfaces with the electrochemical quartz crystal microbalance. Chemical Reviews, v. 92 , n. 6 , p. 1355-1379, 1992.

66 VARELA, H.; MALTA, M.; TORRESI, R. M. Técnicas in situ de baixo custo em eletroquímica: a microbalança a cristal de quartzo. Química Nova, scielo, v. 23, p. 664 - 679, 102000. 
67 DEAKIN, M. R.; BUTTRY, D. A. Electrochemical applications of the quartz crystal microbalance. Analytical Chemistry, v. 60, n. 20, p. 1147A-1154A, 1989.

68 JONES, J. L.; MIEURE, J. P. Piezoelectric transducer for determination of metals at the micromolar level. Analytical Chemistry, v. 41, n. 3, p. 484-490, 1969.

69 CURIE, J.; CURIE, P. Développement, par pression, de l'électricité polaire dans les cristaux hémièdres à faces inclinées. Comptes rendus, v. 91, p. 294-295, 1880.

70 CZANDERnA, A.; LU, C. Applications of Piezoelectric Quartz Crystal Microbalances. New York: Elsevier, 1984. v. 7. (Methods and Phenomena, v. 7).

71 SAUERBREY, G. Verwendung von schwingquarzen zur wägung dünner schichten und zur mikrowägung. Zeitschrift für Physik, v. 155, n. 2, p. 206-222, 1959.

72 ARNAU, A.; SOGORB, T.; JIMéNEZ, Y. A continuous motional series resonant frequency monitoring circuit and a new method of determining Butterworth-Van Dyke parameters of a quartz crystal microbalance in fluid media. Review of Scientific Instruments, v. 71 , n. 6, p. 2563-2571, 2000.

73 VATANKHAH, G. et al. Dependence of the reliability of electrochemical quartzcrystal nanobalance mass responses on the calibration constant, $\mathrm{Cf}$ : analysis of three procedures for its determination. Electrochimica Acta, v. 48, n. 11, p. 1613 - 1622, 2003.

74 PREVIDELlO, B. A. F.; MACHADO, E. G.; VARELA, H. The effect of the alkali metal cation on the electrocatalytic oxidation of formate on platinum. RSC Advances, n. 4, p. 15271-15275, 2014.

75 VASSILIEV, Y.; BAGOTZKY, V.; GROMYKO, V. Kinetics and mechanism of the formation and reduction of oxide layers on platinum part i. oxidation and reduction of platinum electrodes. Journal of Electroanalytical Chemistry and Interfacial Electrochemistry, v. 178, n. 2, p. $247-269,1984$.

76 TRASATTI, S.; PETRII, O. Real surface area measurements in electrochemistry. Journal of Electroanalytical Chemistry, v. 327, n. 1, p. 353 - 376, 1992.

77 IWASITA, T.; VIELSTICH, W.; SANTOS, E. Identification of the adsorbate during methanol oxidation. Journal of Electroanalytical Chemistry and Interfacial Electrochemistry, v. 229, n. 1, p. $367-376,1987$.

78 SHIMAZU, K.; KITA, H. In situ measurements of water adsorption on a platinum electrode by an electrochemical quartz crystal microbalance. Journal of Electroanalytical Chemistry, v. 341, n. 1, p. 361 - 367, 1992.

79 WATANABE, M.; UCHIDA, H.; IKEDA, N. Electrochemical quartz crystal microbalance study of copper ad-atoms on gold and platinum electrodes part i. adsorption of anions in sulfuric acid. Journal of Electroanalytical Chemistry, v. 380, n. 1 , p. $255-260,1995$.

80 GLOAGUEN, F.; LéGER, J.-M.; LAMY, C. An electrochemical quartz crystal microbalance study of the hydrogen underpotential deposition at a pt electrode. Journal of Electroanalytical Chemistry, v. 467, n. 1-2, p. 186 - 192, 1999. 
81 DELMONDE, M. V. F. et al. Electrocatalytic efficiency of the oxidation of small organic molecules under oscillatory regime. Journal of Physical Chemistry C, v. 120, n. 39, p. 22365-22374, 2016.

82 SOBKOWSKI, J.; FRANASZCZUK, K.; DOBROWOLSKA, K. Effect of anions and ph on the adsorption and oxidation of methanol on a platinum electrode.

An International Journal Devoted to all Aspects of Electrode Kinetics, Interfacial Structure, Properties of Electrolytes, Colloid and Biological Electrochemistry, v. 330, n. 1, p. 529-540, jul. 1992.

83 OKAMOTO, H.; KIKUCHI, M.; MUKOUYAMA, Y. Effect of chloride ions on potential oscillation generated by formic acid oxidation. Journal of Electroanalytical Chemistry, v. 622, n. 1, p. 1-9, out. 2008.

84 BATISTA, B. C.; VARELA, H. Open circuit interaction of formic acid with oxidized Pt surfaces: Experiments, modeling, and simulations. Journal of Physical Chemistry C, v. 114, n. 43, p. 18494-18500, 2010.

85 PODLOVCHENKO, B. I.; MANZHOS, R. A.; MAKSIMOV, Y. M. Kinetics and mechanism of interaction between methanol and adsorbed oxygen on a smooth polycrystalline platinum electrode: Transients of the open-circuit potential. Russian Journal of Electrochemistry, v. 42, n. 10, p. 1061 - 1066, 2006.

86 BATISTA, B. C. et al. Autocatalysis in the open circuit interaction of alcohol molecules with oxidized Pt surfaces. Physical Chemistry Chemical Physics, v. 10, p. 6686-6692, 2008. 